\title{
Simulação termomecânica de prismas com blocos de concreto em situação de incêndio
}

\section{Thermomechanical simulation of prisms with concrete blocks in a fire situation}

\author{
Francielle da Silva Rodovalho ${ }^{1}$, Márcio Roberto Silva Corrêa ${ }^{1}$, \\ Jorge Munaiar Neto ${ }^{1}$
}

\footnotetext{
${ }^{1}$ Universidade de São Paulo, Escola de Engenharia de São Carlos, Departamento de Engenharia de Estruturas, Av. Trabalhador Sãocarlense, 400, São Carlos, SP, Brasil.

e-mail: francielle_rodovalho@hotmail.com,marcio.correa@usp.br,jmunaiar@sc.usp.br
}

\begin{abstract}
RESUMO
Incêndios em edificações são frequentes em todo o mundo. Um sistema construtivo amplamente empregado no Brasil e pouco estudado em situação de incêndio é a alvenaria estrutural constituída por blocos de concreto. Em temperatura ambiente pode-se estimar a resistência à compressão axial da alvenaria através da compressão axial de prismas. Além disso, por meio de prismas é possível representar a perda de resistência mecânica devida à deterioração térmica. Assim, o presente trabalho tem como objetivo analisar, em contexto puramente numérico, a resistência mecânica de prismas constituídos por blocos de concreto submetidos à compressão e em situação de incêndio, por meio de simulação termomecânica. Inicialmente, foi simulado um prisma sob compressão à temperatura ambiente com o intuito de validar as propriedades dos materiais nessa condição. Posteriormente, em elevadas temperaturas, foram empregadas propriedades encontradas na literatura técnica. As condições de contorno foram variadas, aplicaram-se dois níveis de carregamento e verificaram-se os casos de prisma com uma e duas faces expostas ao incêndio. Nas simulações numéricas, a aplicação de um nível maior de carregamento, a restrição de deslocamento vertical e a exposição ao incêndio de duas faces antecipou a ruptura do prisma. A falta de restrição rotacional gerou um modo de ruptura diferente do caso com restrição rotacional e em tempo inferior de exposição ao fogo. O emprego de propriedades encontradas na literatura técnica levou a um resultado de tempo de resistência mecânica favorável à segurança.
\end{abstract}

Palavras-chave: blocos de concreto, alvenaria estrutural, elevadas temperaturas, resistência mecânica, análise numérica.

\section{ABSTRACT}

Fires in buildings are frequent in the world. Concrete blockwork masonry is a constructive system widely used in Brazil and poorly studied in a fire situation. At room temperature, the axial compressive strength of the masonry can be estimated by axial compression of prisms. In addition, by means of prisms, it is possible to represent the loss of mechanical resistance due to thermal deterioration. Thus, the purpose of the current study is to verify, in purely numeric context, the mechanical resistance of prisms with concrete blocks under compression in a fire situation, through thermomechanical simulation. Initially, the compression of the prism was simulated at room temperature with the objective of validate the materials' properties. Posteriorly, it was adopted in the study properties based on the technical literature, at high temperatures. The boundary conditions were varied, two levels of loading were applied and cases of prism with one and two faces exposed to fire were verified. In the simulations, the application of a higher loading level, the vertical displacement restriction and the double-sided fire exposure anticipated the prism failure. The lack of rotational restraint generated a mode of rupture different from the case with rotational restraint and in less time of fire. The use of properties found in the technical literature led to a time of mechanical resistance favorable to safety.

Keywords: concrete blocks, structural masonry, high temperatures, mechanical resistance, numerical analysis.

\section{INTRODUÇÃO}


Em todo o mundo os incêndios em edificações são frequentes, fazendo milhares de vítimas a cada ano, causando também perdas materiais. Conforme o Centre of Fire Statistics - CTIF [1], esse tipo de incêndio foi responsável por $35,5 \%$ das ocorrências no ano de 2016.

A resistência ao fogo de uma estrutura está vinculada ao tempo em que ela é capaz de suportar as ações para as quais foi projetada, quando exposta a elevadas temperaturas. O tempo requerido de resistência ao fogo - TRRF leva em consideração o tempo necessário para que os ocupantes possam abandonar o edifício em segurança ou serem socorridos. Conforme o EUROCODE 6 PART 1-2:2005 [2], os três principais critérios de resistência ao fogo são:

- $\quad$ Isolamento térmico (I), o qual é considerado atendido enquanto em qualquer ponto da superfície não exposta ao fogo, a variação de temperatura não exceder $180^{\circ} \mathrm{C}$ e a variação de temperatura média nesta mesma superfície não exceder $140^{\circ} \mathrm{C}$;

- $\quad$ Resistência mecânica (R), o qual é satisfeito enquanto a função de suporte de carga é mantida na exposição ao fogo;

- $\quad$ Estanqueidade (E), quando não ocorrem rachaduras ou aberturas que permitam a passagem de chamas e gases através do elemento.

A alvenaria estrutural, por ser um sistema construtivo amplamente empregado no Brasil, deve ser estudada em situação de incêndio. De acordo com LEITE et al. [3], cada país possui especificações de geometria, espessura e resistência a serem seguidas, devido às diferentes composições mineralógicas dos agregados utilizados. Esses fatores regionais dificultam o uso de normas internacionais. Apesar de o Brasil ainda não possuir métodos normatizados de dimensionamento de alvenaria em situação de incêndio, alguns ensaios nacionais foram elaborados com paredes formadas por blocos cerâmicos submetidas a elevadas temperaturas.

ROSEMANN [4] analisou experimental e numericamente o comportamento de paredes constituídas por blocos cerâmicos não carregadas e em situação de incêndio. Foram analisados experimentalmente os critérios de isolamento térmico e estanqueidade, a aplicação de revestimento em argamassa e preenchimento das maiores cavidades dos blocos com areia. $\mathrm{O}$ autor constatou que após serem atingidas as temperaturas limites de isolamento térmico, as paredes se mantiveram estanques. Além disso, ROSEMANN [4] também verificou que a capacidade de isolamento térmico, que inicialmente era de 106 minutos, foi elevada em $280 \%$ com a aplicação de revestimento e preenchimento das cavidades da alvenaria.

RIGÃO [5] avaliou experimentalmente o comportamento da argamassa, de prismas e de pequenas paredes carregadas, constituídas por blocos cerâmicos em situação de incêndio. $\mathrm{O}$ autor verificou que a argamassa, após ser submetida à temperatura de $900^{\circ} \mathrm{C}$, não apresentava resistência alguma e os prismas possuíam aproximadamente $50 \%$ de suas resistências iniciais. As pequenas paredes foram construídas com dimensões de $89 \mathrm{~cm}$ x $100 \mathrm{~cm}$ e espessura de $14 \mathrm{~cm}$ e, devido à restrição vertical imposta, ocorreram incrementos de carga. Após o incêndio, as pequenas paredes se mantiveram estanques, entretanto, não foi possível comparar os resultados com normas de segurança, pois a elevação de temperatura não seguiu a curva de incêndiopadrão proposta pela ISO 834-1:1999 [6].

Sobre a alvenaria estrutural formada por blocos de concreto, estão presentes em CHICHIERCHIO [7] resultados finais de resistência ao fogo de uma parede com função portante, com blocos de dimensões de 14 $\mathrm{cm}$ x $19 \mathrm{~cm}$ x $39 \mathrm{~cm}$ da antiga empresa Tecprem. A alvenaria recebeu carregamento para o qual foi dimensionada. Conforme o autor, a parede desempenhou a função de corta-fogo durante 1 hora e por 4 horas se manteve estável ao fogo e desempenhou a função de para-chamas.

Em BLOCO BRASIL [8] são apresentados resultados finais de ensaios de resistência ao fogo de alvenarias constituídas por blocos de concreto de classes C e B, com dimensões iguais a $14 \mathrm{~cm} \mathrm{x} 19 \mathrm{~cm}$ x $39 \mathrm{~cm}$. Ambas as paredes foram revestidas nas duas faces com argamassa industrializada com espessura de 1,5 cm. Porém, aos 9 minutos de ensaio ocorreu o desprendimento do revestimento nas faces expostas ao fogo. A parede composta por blocos de classe B recebeu carregamento axial igual a $10.000 \mathrm{kgf} / \mathrm{m}$, mantido constante durante o ensaio. A temperatura limite do critério de isolamento térmico foi atingida aos 107 minutos e os critérios de estanqueidade e resistência mecânica foram considerados atendidos durante os 120 minutos de ensaio, não sendo atingida a ruptura da parede.

Em RODOVALHO e CORRÊA [9] foram gerados os campos térmicos dos prismas e avaliado o critério de isolamento térmico. No presente trabalho, o objetivo central é analisar o critério de resistência mecânica dos prismas constituídos por blocos de concreto. Para isso, foram feitas simulações termomecânicas utilizando o software ABAQUS/CAE na versão 6.14.

As edificações que passam por situação de incêndio teoricamente possuem carregamento em serviço 
em temperatura ambiente e em seguida ocorre a ação excepcional do fogo. A curva de incêndio-padrão proposta pela ISO 834-1:1999 [6] tem início com a temperatura do ambiente. Por isso, na simulação termomecânica é necessária a inserção das propriedades mecânicas dos materiais em temperatura ambiente e em elevadas temperaturas. Assim, inicialmente foi realizada a simulação de compressão em temperatura ambiente do prisma de três blocos e argamassamento parcial, com o intuito de validar as propriedades, comparando o resultado com experimento realizado por OLIVEIRA [10].

Conforme especifica a ABNT NBR 16522:2016 [11] para a determinação da resistência à compressão de prismas, esses devem ser constituídos por dois blocos e argamassamento total. Desta forma, são apresentados os resultados para esse caso, utilizando-se as mesmas propriedades empregadas para o prisma de três blocos e argamassamento parcial.

A modelagem termomecânica foi realizada com o prisma de dois blocos e argamassamento total, utilizando-se o plano comum de simetria das simulações térmica e termomecânica. Justifica-se o emprego do prisma pela possibilidade de representar a perda de resistência mecânica devida à deterioração térmica. Além disso, destaca-se o elevado esforço computacional no caso de simulação termomecânica.

Conforme a ABNT NBR 5628:2001 [12], as vinculações e os apoios devem ser feitos de acordo com as condições de uso e esses dependem das definições em projeto e execução da construção. Por isso, optou-se por variar as vinculações nos modelos das simulações termomecânicas.

\section{MATERIAIS E MÉTODOS}

\subsection{Simulações de compressão em temperatura ambiente}

A caracterização do bloco de concreto e da argamassa, considerados nas simulações, foi realizada no Laboratório de Estruturas da Escola de Engenharia de São Carlos - USP por OLIVEIRA [10]. Nesse trabalho foram realizados ensaios de compressão de prisma de três blocos com argamassamento parcial. Assim, com o intuito de validar as propriedades dos materiais, foi feita a simulação de compressão de um prisma com as mesmas características. Por meio dos ensaios, os blocos foram caracterizados com classe de resistência A como especifica a ABNT NBR 6136:2016 [13], com resistência característica à compressão axial de 8,68 MPa na área bruta.

Para as dimensões externas do bloco foram utilizados os valores médios obtidos por OLIVEIRA [10]. O interior do bloco foi simplificado, substituindo-se as mísulas curvas por ângulos retos. Assim, as dimensões das paredes do bloco foram estimadas de modo que a média entre área superior e inferior resultasse o mais próximo do valor de área líquida de $297,95 \mathrm{~cm}^{2}$ obtida por OLIVEIRA [10]. As dimensões do bloco empregadas nas simulações estão presentes na Figura 1.

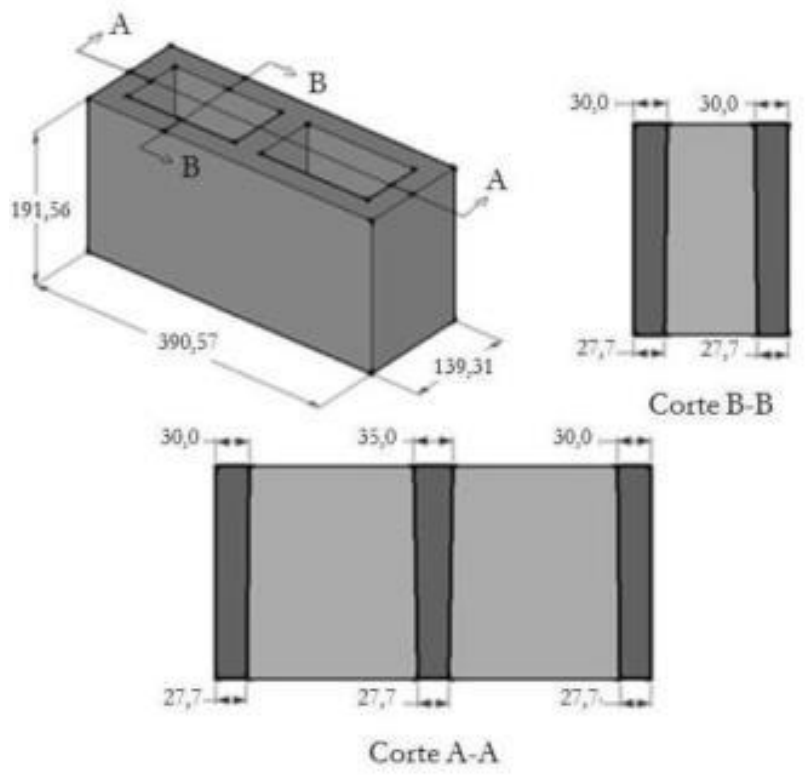

Figura 1: Dimensões do bloco de concreto utilizadas nas simulações (mm). 
No bloco de concreto foram utilizados 6080 elementos sólidos pertencentes à família "tensão-3D" do tipo C3D8R, os quais possuem oitos nós e três graus de liberdade por nó, com lados de dimensões aproximadas de $1 \mathrm{~cm}$ e integração reduzida. A malha utilizada no bloco encontra-se esquematizada na Figura 2.

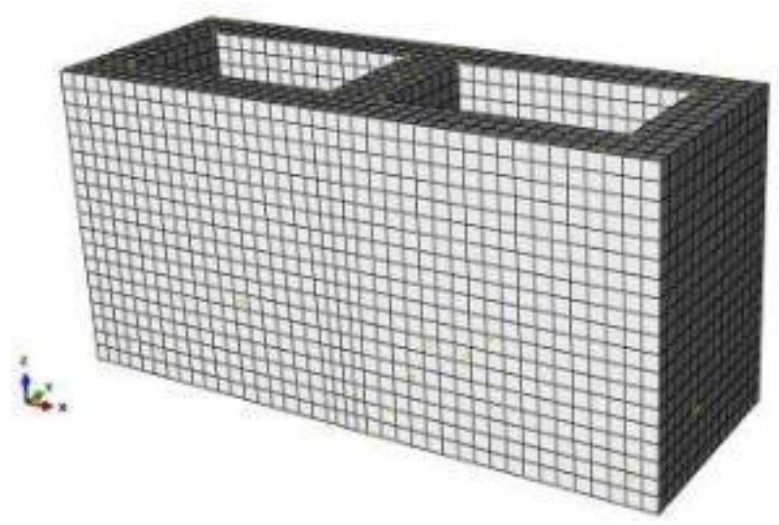

Figura 2: Malha utilizada no bloco de concreto.

O módulo de elasticidade inicial do concreto, igual a $20.141 \mathrm{MPa}$, foi obtido por meio da curva tensão-deformação com clip-gages, disponível em OLIVEIRA [10]. Adotou-se 0,2 como coeficiente de Poisson e utilizou-se o modelo de plasticidade do ABAQUS, Concrete damaged plasticity.

A curva tensão-deformação inserida no software foi a proposta por CARREIRA e CHU [14]. Nesse modelo foram inseridos os valores de 18,5 MPa de resistência à compressão do concreto, 3\%o de deformação de pico e $20.141 \mathrm{MPa}$ de módulo de elasticidade. O dano à compressão foi calculado conforme o modelo proposto em BIRTEL e MARK [15].

Para a resistência à tração do concreto foi adotado valor igual a 0,96 MPa, assim como OLIVEIRA [10] empregou em suas simulações. O comportamento à tração foi inserido no ABAQUS através da energia de fratura na tração em N/mm calculada conforme sugere CEB-FIP MC 1990 apud FIB [16] disposto na Equação 1, indicada para diâmetro máximo do agregado igual a $8 \mathrm{~mm}$, obtendo-se aproximadamente 0,04 $\mathrm{N} / \mathrm{mm}$ ou $40 \mathrm{~N} / \mathrm{m}$ :

$$
G_{f I}=0,025\left(\frac{f_{c}^{\prime}}{10}\right)^{0,7}
$$

onde:

$\mathrm{G}_{\mathrm{fI}}$ é a energia de fratura na tração;

$f^{\prime}{ }_{c}$ é a resistência à compressão do concreto em MPa.

Os demais parâmetros necessários para o modelo de plasticidade do software foram calibrados para que se obtivesse o resultado numérico mais próximo do experimental.

A argamassa utilizada por OLIVEIRA [10] foi do tipo i com traço em volume (cimento:cal:areia) de 1:0,5:4,5, traço em massa de 1:0,33:6,38 e fator água/cimento igual a 1,17. Na modelagem numérica, as dimensões foram definidas de modo que a superfície superior da argamassa se adequasse à base do bloco, sua superfície inferior se acomodasse ao topo do bloco e $1 \mathrm{~cm}$ de espessura. Foram utilizados elementos finitos do tipo C3D8R com dimensões dos lados próximas de $1 \mathrm{~cm}$. Empregaram-se 260 elementos no argamassamento parcial e 320 no argamassamento total dispostos conforme ilustra a Figura 3. 


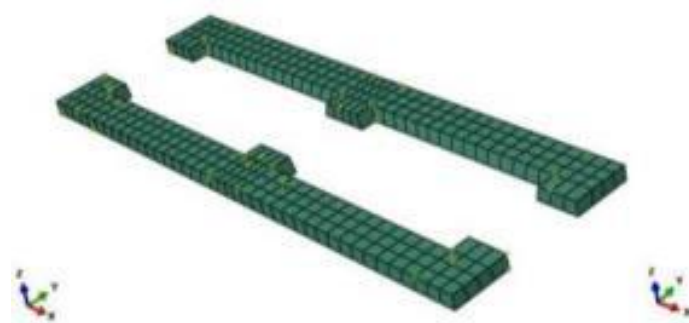

Argamassamento parcial

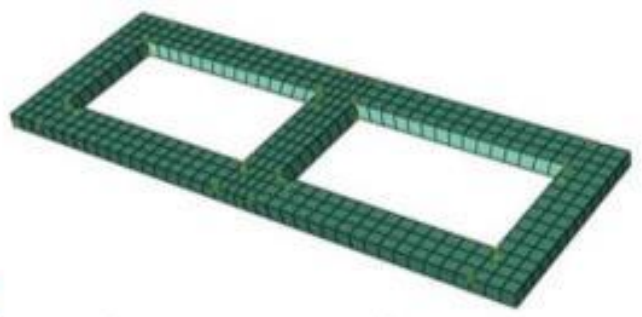

Argamassamento total

Figura 3: Malhas utilizadas nas juntas de argamassa.

O módulo de elasticidade inicial da argamassa foi igual a 11,39 GPa, resistência à compressão igual a 6,93 MPa e deformação de pico igual a 1,85\%, valores disponíveis em OLIVEIRA [10]. A curva tensãodeformação e o dano à compressão foram calculados também conforme os modelos de CARREIRA e CHU [14] e BIRTEL e MARK [15], respectivamente. Esses valores foram inseridos no modelo Concrete damaged plasticity do ABAQUS.

A resistência à tração da argamassa foi estimada conforme a média aritmética dos valores da razão (resistência à tração)/(resistência à compressão) aos 28 dias, disponível em BUTTLER et al. [17]. Sendo a média da razão (resistência à tração)/(resistência à compressão) de 12,40\%, estimou-se a resistência à tração da argamassa em 0,86 MPa. A energia à fratura na tração foi adotada como $50 \mathrm{~N} / \mathrm{m}$, conforme IZQUIERDO [18]. O restante dos parâmetros do material necessários ao modelo de plasticidade foi calibrado para a obtenção do resultado numérico mais próximo do experimental. Estes parâmetros estão presentes na Tabela 1.

Tabela 1: Parâmetros necessários para o modelo de plasticidade.

\begin{tabular}{c|l|l|l|l|l}
\hline \multicolumn{2}{c|}{ ÂNGULO DE DILATÂNCIA } & EXCENTRICIDADE & $\begin{array}{c}* \\
\sigma_{b 0} / \sigma_{c 0}\end{array}$ & $\begin{array}{c}{ }^{* *} \\
\mathbf{K}_{\mathbf{c}}\end{array}$ & VISCOSIDADE \\
\hline BLOCO & 27 & 0,1 & 1,14 & 0,666 & 0,0001 \\
\hline ARGAMASSA & 35 & 0,1 & 1,4 & 0,667 & 0,01 \\
\hline
\end{tabular}

* $\sigma_{\mathrm{b} 0}$ e $\sigma_{\mathrm{c} 0}$ representam a resistência à compressão biaxial e uniaxial, respectivamente.

** $\mathrm{K}_{\mathrm{c}}$ define o formato da superfície de resistência do concreto, modificando o critério de DruckerPrager.

Os blocos e juntas de argamassa foram unidos através da restrição "tie”, a qual vincula o deslocamento do nó de um elemento ao nó de outro elemento. Tal simplificação adotada se justifica uma vez que na ruptura à compressão dos prismas não se observou o descolamento da interface argamassa/bloco.

Para simular a compressão nos prismas foram discretizadas duas placas, uma que serviu de apoio acoplada a um nó de referência com todos os graus de liberdade restritos, e outra na qual se restringiram os deslocamentos nos eixos X e Y, e se aplicou deslocamento de $2 \mathrm{~mm}$ em pequenos incrementos no eixo Z. Cada placa foi idealizada com dimensões iguais a $42 \mathrm{~cm}$ x $15 \mathrm{~cm}$, espessura de $3 \mathrm{~cm}$ e 1890 elementos do mesmo tipo do bloco. Para simular um material rígido, empregou-se elevado módulo de elasticidade, se comparado ao valor atribuído ao concreto, e coeficiente de Poisson nulo. 
Nas interfaces placa/bloco foi atribuída ao comportamento normal a opção "Hard contact", que impossibilita a penetração de um material em outro, com a opção de permitir a separação após o contato. Já no comportamento tangencial foi inserido o coeficiente de atrito igual a 0,6. O esquema para a simulação de compressão dos prismas está ilustrado na Figura 4.

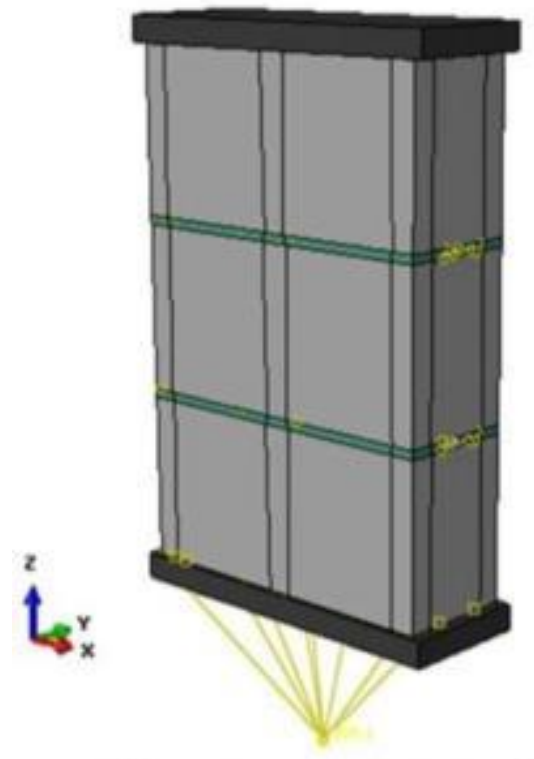

3 blocos com argamassamento parcial

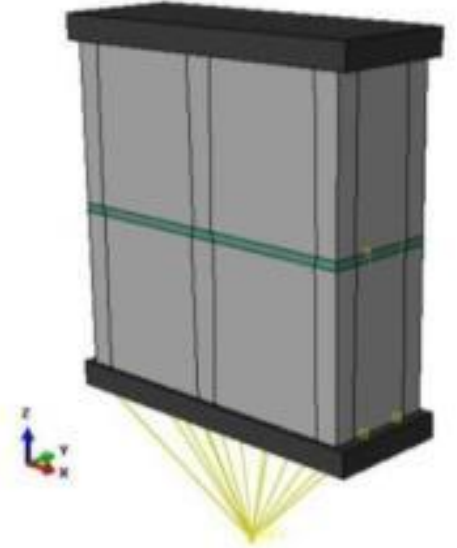

2 blocos com argamassamento total

Figura 4: Esquema de compressão dos prismas.

\subsection{Simulações termomecânicas}

As variações de resistência à compressão do concreto e argamassa foram adotadas conforme o EUROCODE 2 PART 1-2:2004 [19]. Essa norma apresenta a variação da razão entre a resistência do material em determinada temperatura e sua resistência inicial em temperatura ambiente $\left.\left(f_{c, T} / f_{c k}\right)\right)$ a deformação correspondente à máxima tensão de compressão $\left(\varepsilon_{\mathrm{c} 1, \mathrm{~T}}\right)$ e a deformação última $\left(\varepsilon_{\mathrm{cul}, \mathrm{T}}\right)$, em ambos os casos, conforme a temperatura, adotando-se como linear o trecho descendente do diagrama tensão-deformação.

Optou-se por utilizar as propriedades do concreto com agregados silicosos para o material do bloco e argamassa, pois o agregado miúdo do concreto e argamassa é a areia. A ABNT NBR 15200:2012 [20] sugere os mesmos valores para o fator de redução de resistência do concreto em função da temperatura. O módulo de elasticidade dos materiais dependente da temperatura foi obtido traçando-se a curva tensão-deformação a partir da Equação 2 e calculando-se a inclinação do trecho retilíneo entre 5 e $33 \%$ da resistência à compressão.

$$
\sigma_{(T)}=\frac{3 \varepsilon f_{c, T}}{\varepsilon_{c 1, T}\left(2+\left(\frac{\varepsilon}{\varepsilon_{c 1, T}}\right)^{3}\right)}
$$

onde:

$\sigma_{\mathcal{E}} \leq \underset{\mathcal{E}}{ } \underset{\varepsilon}{\varepsilon}$ a tensão em determinada temperatura correspondente à deformação $\varepsilon$;

$f_{c, T}$ é a resistência do material em determinada temperatura;

$\varepsilon_{c 1, T}$ representa a deformação correspondente à máxima tensão de compressão.

As deformações correspondentes à máxima tensão e deformações últimas do concreto e da argamassa foram calculadas fazendo-se proporção entre os valores obtidos no EUROCODE 2 PART 1-2:2004 [19] e os valores à temperatura ambiente. Por fim, os valores de módulo de elasticidade, resistência à compressão e 
deformação correspondente à máxima tensão foram inseridos no modelo de CARREIRA e CHU [14], utilizando-se o mesmo modelo de curva para o trecho ascendente já empregado em temperatura ambiente, também em elevadas temperaturas. O dano à compressão foi calculado conforme o modelo de BIRTEL e MARK [15]. Nas Figuras 5 e 6 estão ilustradas as curvas tensão-deformação conforme a temperatura, empregadas nos blocos e argamassa, respectivamente.
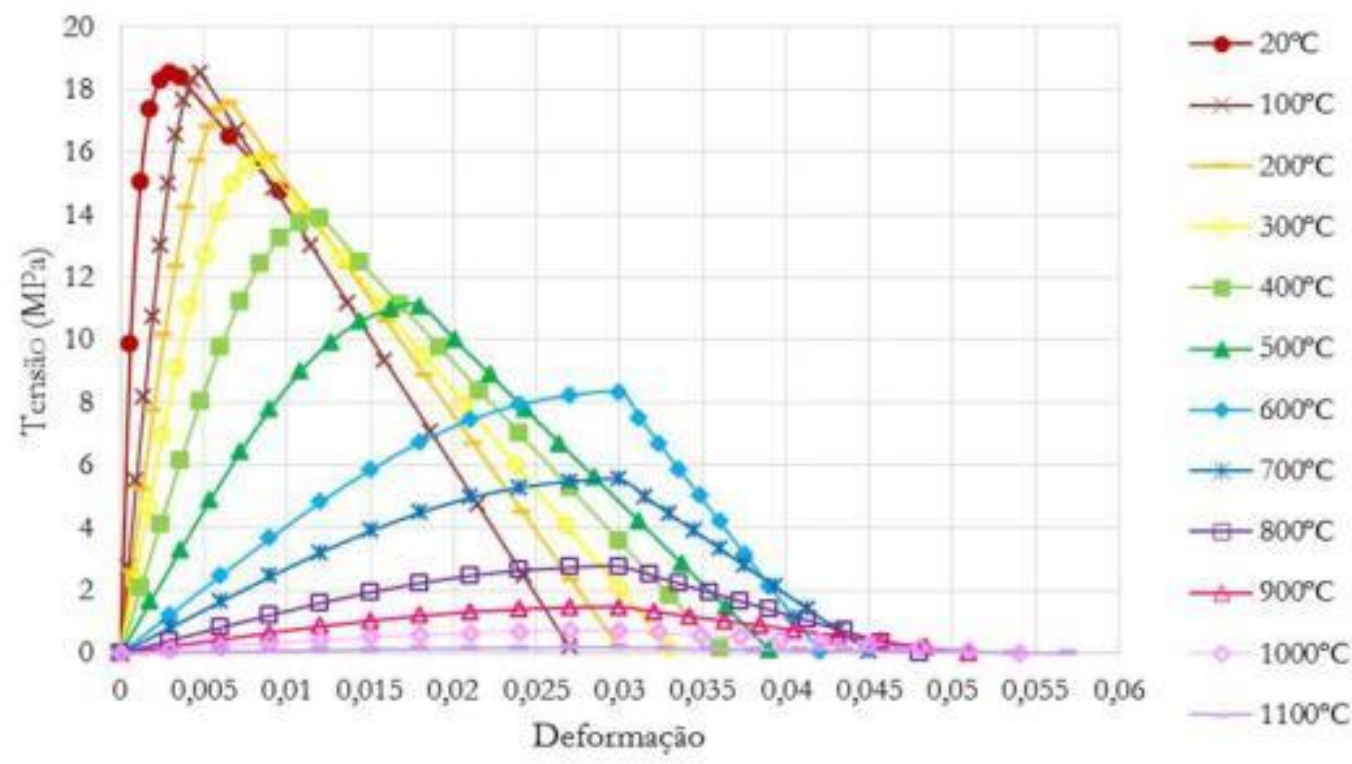

Figura 5: Curvas tensão-deformação conforme a temperatura do bloco.

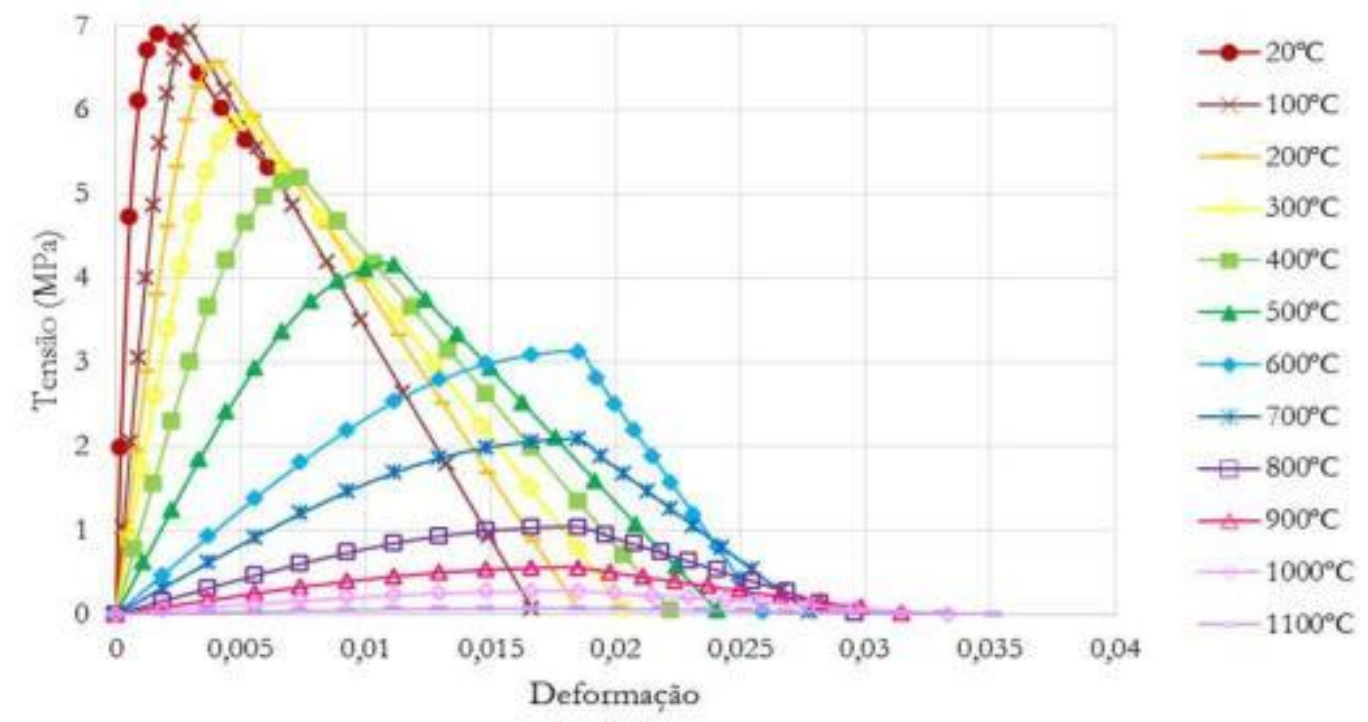

Figura 6: Curvas tensão-deformação conforme a temperatura da argamassa.

Para a temperatura de $20^{\circ} \mathrm{C}$ foram utilizadas as curvas empregadas na compressão do prisma em temperatura ambiente. As curvas referentes às temperaturas de 100 e $1100^{\circ} \mathrm{C}$ foram retiradas da simulação devido a problemas de convergência, ocorridos provavelmente porque em $100^{\circ} \mathrm{C}$ se mantém a resistência inicial com um módulo de elasticidade inferior ao de $20^{\circ} \mathrm{C}$ e em $1100^{\circ} \mathrm{C}$ os valores de tensão são muito baixos, próximos de zero.

A resistência à tração em elevadas temperaturas do concreto e argamassa foi calculada proporcionalmente à razão (resistência à tração)/(resistência à compressão) em temperatura ambiente. A energia de fratura 
à tração do concreto foi calculada por meio da Equação 1, enquanto a da argamassa foi estimada por meio de proporção com o valor em temperatura ambiente e a perda de resistência conforme o EUROCODE 2 PART 1-2:2004 [19].

Os coeficientes de dilatação linear para o bloco e para a argamassa foram adotados como $9,0 \times 10^{-6 \circ} \mathrm{C}^{-}$ 1, sendo este o único valor sugerido pela ABNT NBR 15961-1:2011 [21] para o caso de ausência de dados experimentais, com temperatura de referência de $20^{\circ} \mathrm{C}$. SCHNEIDER [22] apresenta a deformação térmica para concretos com diferentes tipos de agregados. Conforme o autor, acima de $800^{\circ} \mathrm{C}$ não ocorre expansão do concreto com basalto, então se considerou que acima dessa temperatura os materiais não se dilatam. $\mathrm{O}$ carregamento foi aplicado na placa superior por meio de um passo inicial em pequenos incrementos. Em seguida, iniciou-se o passo de incêndio, no qual se inserem os dados de temperatura nodais dos elementos obtidos na modelagem térmica. Verificou-se o caso de carregamento constante durante a simulação de incêndio, conforme especifica a ABNT NBR 5628:2001 [12].

De acordo com a ABNT NBR 5628:2001 [12], o carregamento aplicado deve ser da mesma ordem de grandeza dos produzidos em situação de uso, em temperatura ambiente. Assim, inicialmente foi calculada a resistência característica à compressão dos 12 prismas ensaiados por OLIVEIRA [10] e estimou-se a resistência característica do prisma simulado, uma vez que a comparação para validação da modelagem foi feita através dos valores médios de resistência.

Em seguida estimou-se qual seria o valor de carregamento aplicado em uma parede constituída com os mesmos materiais do prisma. Para isso considerou-se que a resistência da parede é cerca de $70 \%$ da resistência do prisma e o coeficiente de ponderação de resistência da alvenaria igual à 2,0, conforme a ABNT NBR 15961-1:2011 [21], o coeficiente redutor devido à esbeltez da parede estimado em 0,85, e o coeficiente de ponderação para combinações normais de ações permanentes de 1,4.

Esse resultado foi arredondado para $20 \%$ da resistência característica do prisma, fpk, equivalente a cerca de $30 \%$ da resistência característica de uma parede constituída pelos mesmos materiais. Aplicou-se também o que se considera teoricamente o "carregamento em serviço do prisma", com o valor correspondente a $35 \% \mathrm{fpk}$.

Foram verificadas as condições de contorno utilizadas em alguns diferentes trabalhos. RUSSO e SCIARRETTA [23] apresentaram um esquema de uma parede carregada com a extremidade inferior engastada e a superior com engaste móvel, possibilitando o deslocamento vertical do topo da parede.

NGUYEN e MEFTAH [24] utilizaram em seus experimentos uma viga para a distribuição dos esforços gerados por células de carga fixas horizontalmente. Os autores não apresentaram informações sobre a restrição rotacional. Já a extremidade inferior foi unida a uma base de concreto com junta de argamassa.

NADJAI et al. [25] afirmam que existia uma restrição rotacional em seus experimentos. Conforme os autores, após a rotação da extremidade superior da parede no valor de um ângulo $\theta$ lim desconhecido, a placa gera um momento fletor adicional.

Assim, para a placa superior foi necessária a criação de um nó de referência, possibilitando o impedimento do giro provocado pela dilatação diferencial. Verificaram-se os casos com e sem restrição rotacional. As condições de contorno da placa inferior foram mantidas conforme a simulação de compressão em temperatura ambiente. Conforme feito em RIGÃO [5] analisou-se também o caso de restrição de deslocamento vertical após a aplicação do carregamento. Devido à utilização da simetria no plano formado pelos eixos $\mathrm{Z}$ e $\mathrm{Y}$, restringiu-se o deslocamento em $\mathrm{X}$ de todo o centro do prisma e placas. O esquema da simulação termomecânica do prisma está presente na Figura 7. 


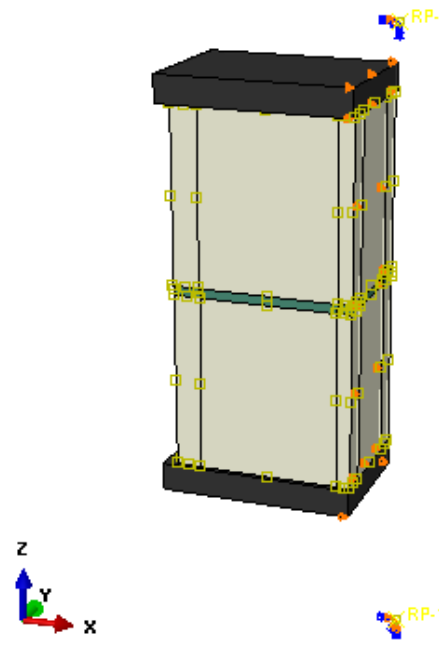

Figura 7: Esquema da simulação termomecânica do prisma.

\subsubsection{Prisma com duas faces expostas ao incêndio}

A fim de verificar a ruptura do prisma em uma situação onde a restrição rotacional da placa de compressão não influenciaria os resultados, simulou-se o prisma com duas faces expostas ao incêndio. Apesar da pouca possibilidade de se ter a mesma intensidade de incêndio em ambos os lados e no mesmo instante, aplicou-se a curva ISO 834-1:1999 [6] nas duas faces do prisma, com objetivo exploratório.

As propriedades térmicas adotadas foram as mesmas apresentadas em RODOVALHO e CORRÊA [9], considerou-se como temperatura inicial $20^{\circ} \mathrm{C}$ e foi simulada a aplicação de carregamento nos valores de 20 e $35 \%$ fpk.

\subsubsection{Prisma com uma face exposta ao incêndio}

Para o prisma carregado e com uma face exposta ao fogo, inicialmente foram verificados os casos de carregamento constante com e sem restrição rotacional. Em seguida verificou-se a aplicação de restrição de deslocamento vertical após a aplicação do carregamento inicial.

\section{RESULTADOS}

\subsection{Simulações de compressão em temperatura ambiente}

No diagrama tensão-deformação do prisma disponível em OLIVEIRA [10] é possível observar a resistência à compressão média na área bruta de aproximadamente 4,93 $\mathrm{MPa}$, equivalente a 8,99 $\mathrm{MPa}$ na área líquida e deformação de pico de $0,72 \%$. Numericamente obteve-se para o prisma de três blocos e argamassamento parcial a deformação de pico igual a $0,74 \%$ e resistência à compressão na área líquida de 8,63 MPa, correspondendo a erros de 2,78 e $4,00 \%$, respectivamente. A máxima tensão foi atingida com a força igual a 257,18 $\mathrm{kN}$.

Na simulação de compressão do prisma de dois blocos e argamassamento total, a resistência obtida foi de 10,65 MPa na área líquida, para força de $317,15 \mathrm{kN}$, com deformação de pico de 1,12\%o. Na Figura 8 estão ilustrados os diagramas tensão-deformação experimental e numéricos. Nessa mesma Figura se observa uma proximidade entre os diagramas tensão-deformação para os resultados numérico e experimental do prisma de três blocos e argamassamento parcial até o pico de tensão máxima. Após esse pico não foi possível estabelecer análise comparativa, pois se perdeu o significado da deformação experimental. 


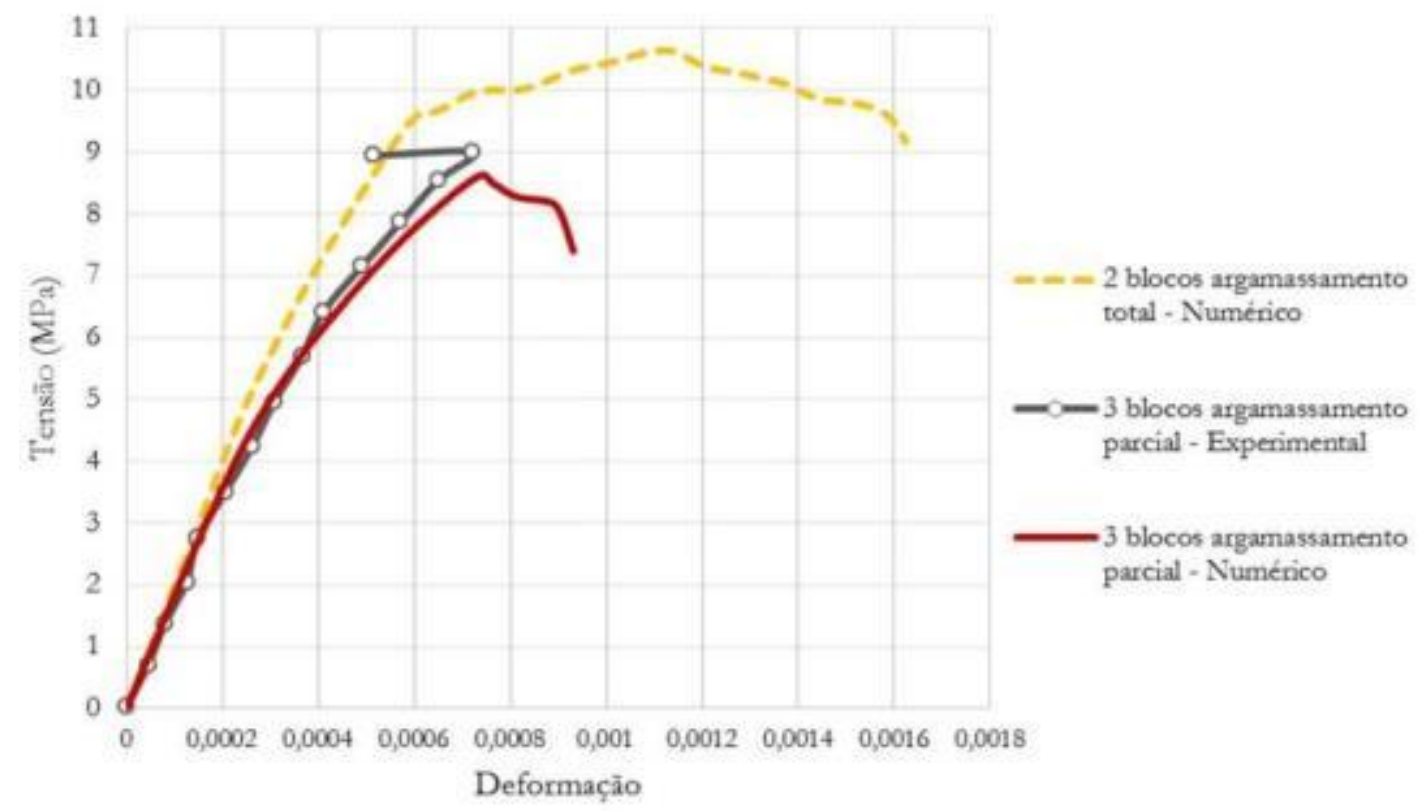

Figura 8: Diagramas tensão-deformação dos prismas.

A Figura 9 apresenta a distribuição de tensões principais, máximas e mínimas, no prisma de três blocos com argamassamento parcial no instante de força máxima de $257,18 \mathrm{kN}$. 
S, Max. Principal (Avg: $75 \%$ )

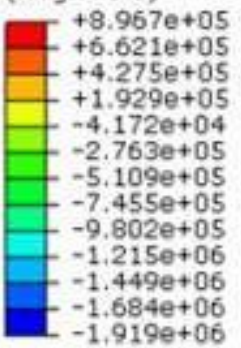

Max: +8.967 e+05

Elem: BLOCO-2.3547

Node: 715

Min: $-1.919 e+06$

Elem: ARGAMASSA-1.3

Node: 436
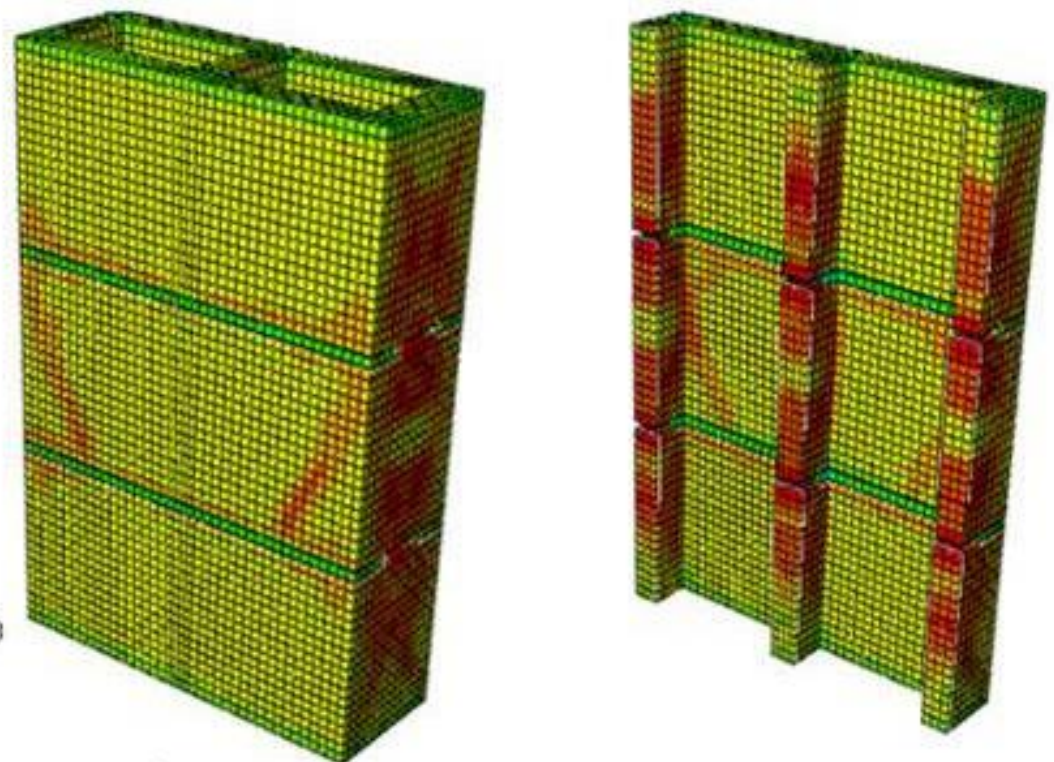

\& Step: Step-1, Deslocamento

E. Increment 20: Step Time $=0.2242$

S, Min. Principal (Avg: 75\%)

$+1.596 \mathrm{e}+05$

$-1.021 \mathrm{e}+06$

$-2.201 e+06$

$-3.382 e+06$

$-4.562 \mathrm{e}+06$

$-5.742 e+06$

$-6.923 e+06$

$-8,103 e+06$

$-9.283 \mathrm{e}+06$

$-1.046 \mathrm{e}+07$

$-1.164 \mathrm{e}+07$

$-1.282 e+07$

$-1.401 e+07$

Max: $+1.596 e+05$

Elem: BLOCO-2.3544

Node: 3456

Min: $-1.401 e+07$

Elem: BLOCO-1.2739

Node: 3007
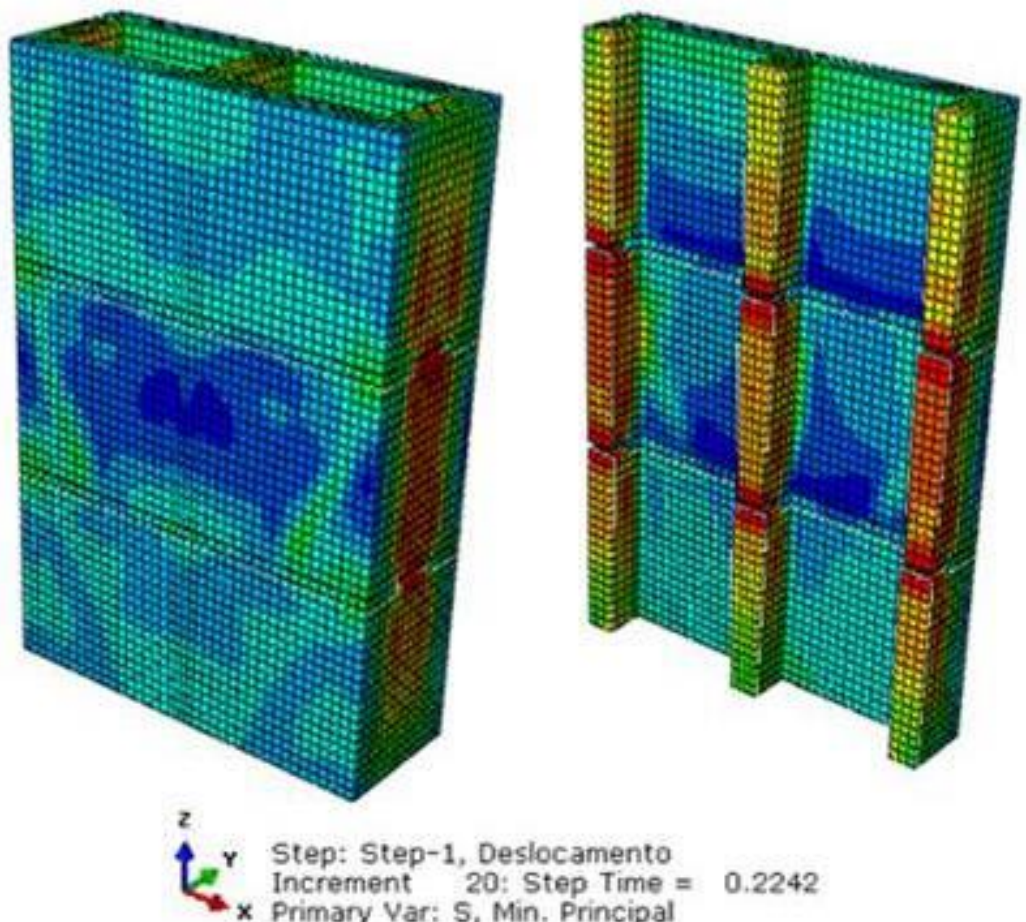

Step: Step-1, Deslocamento

Increment 20: Step Time $=0.2242$

Primary Var: S, Min. Principal

Figura 9: Distribuição de tensões principais no prisma de três blocos com argamassamento parcial (Pa).

Através da Figura 9 é possível notar que nos septos transversais são desenvolvidas tensões de tração. Nas extremidades dos septos são desenvolvidas tensões de compressão devidas ao confinamento imposto pelas placas. Na Figura 10 é apresentado o modo de ruptura do prisma de três blocos com argamassamento parcial obtido experimentalmente por OLIVEIRA [10]. 

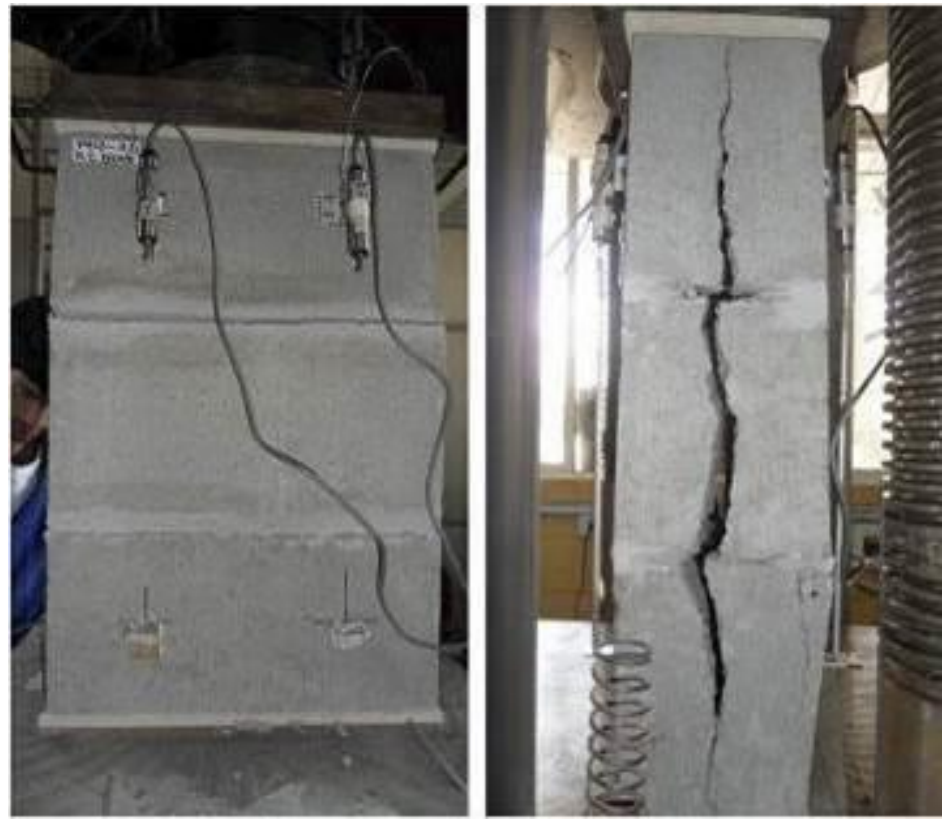

Figura 10: Modo de ruptura do prisma de três blocos com argamassamento parcial. Fonte: OLIVEIRA [10]

Observa-se que a ruptura ocorre nos septos transversais dos blocos, na mesma região em que se desenvolveram as tensões principais máximas da modelagem numérica. Assim, consideraram-se validadas as propriedades empregadas na simulação, até o instante de força máxima.

A distribuição de tensões principais, máximas e mínimas, do prisma de dois blocos e argamassamento total é apresentada na Figura 11, correspondente ao instante de força máxima igual a 317,15 kN. 
S, Max. Principal (Avg: 75\%)
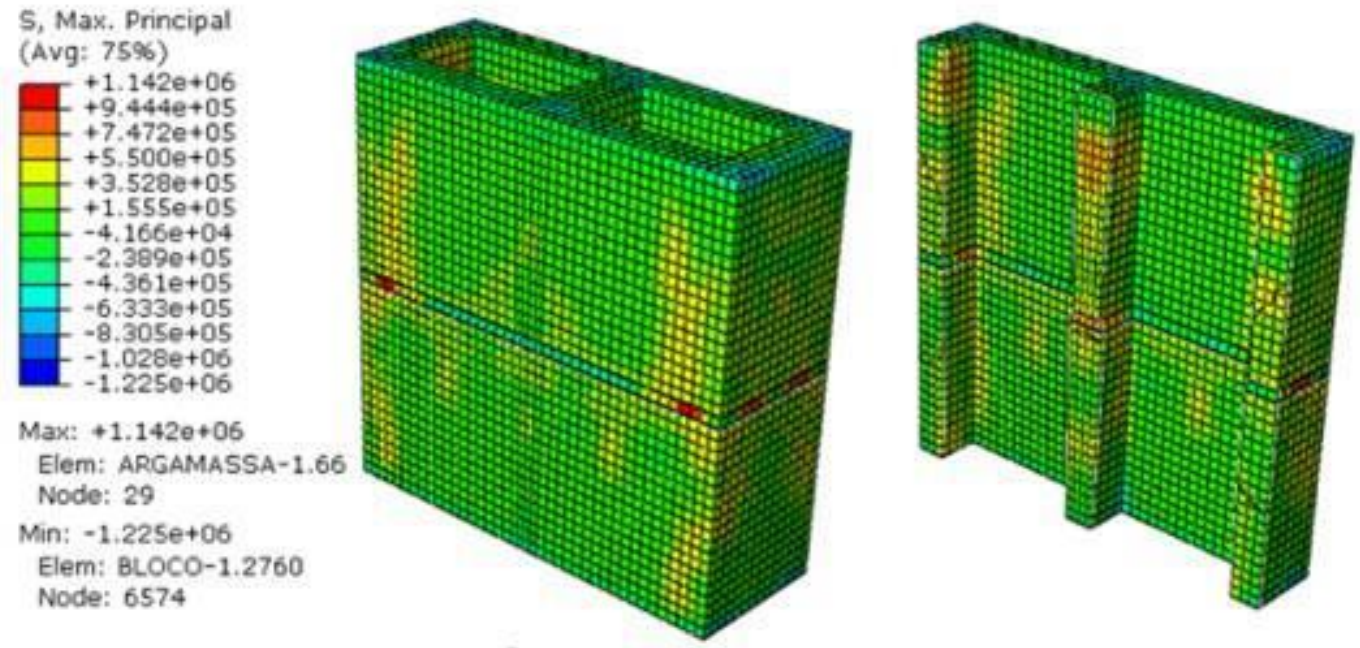

Node: 6574

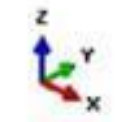

Step: Step-1, Deslocamento

Increment $47:$ Step Time $=0.2240$

Primary Var: S, Max. Principal

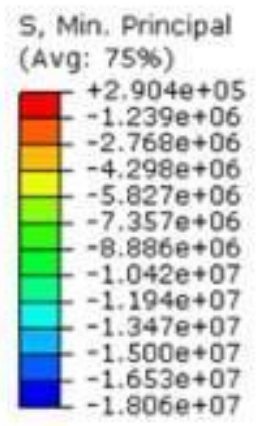

Max: +2.904e+05

Elem: BLOCO-1.3723

Node: 584

Min: $-1.806 \theta+07$

Elem: BLOCO-2.1021

Node: 200
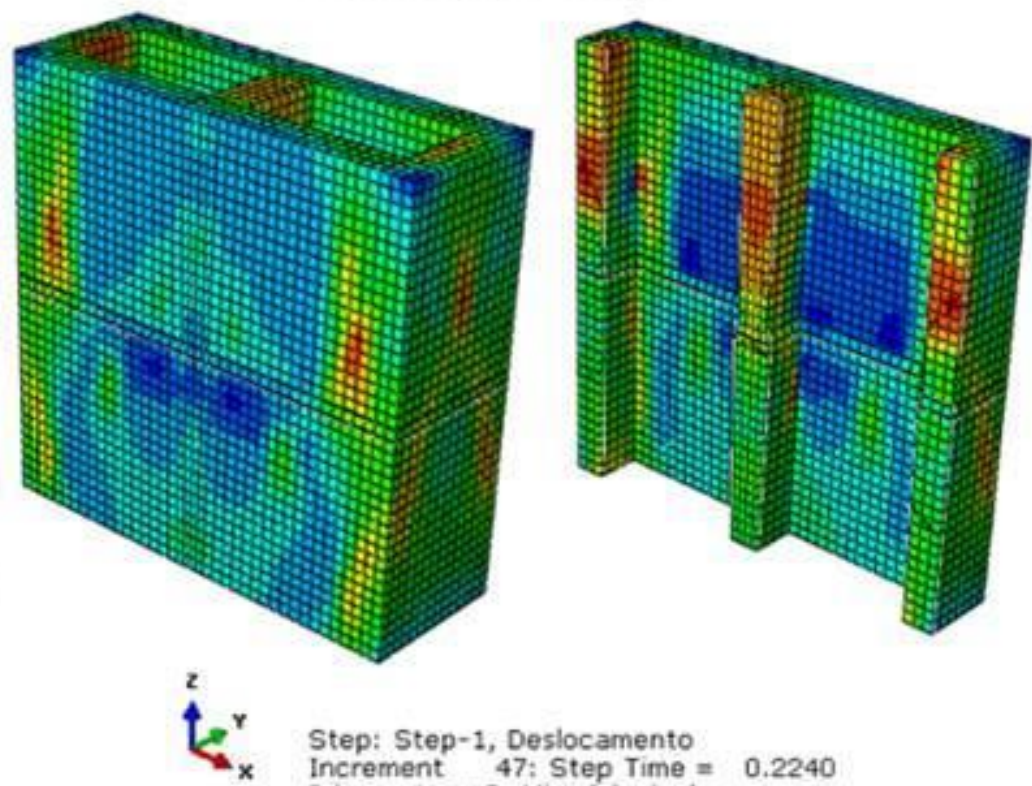

Step: Step-1, Deslocamento

Increment $47:$ Step Time $=0.2240$

Primary Var: S, Min. Principal

Figura 11: Distribuição de tensões principais no prisma de dois blocos com argamassamento total (Pa).

É possível notar na Figura 11 tensões máximas iniciando-se nas laterais da junta de argamassa e se estendendo aos blocos. O modo de ruptura do prisma de dois blocos com argamassamento total obtido experimentalmente por IZQUIERDO [18] está ilustrado na Figura 12. 

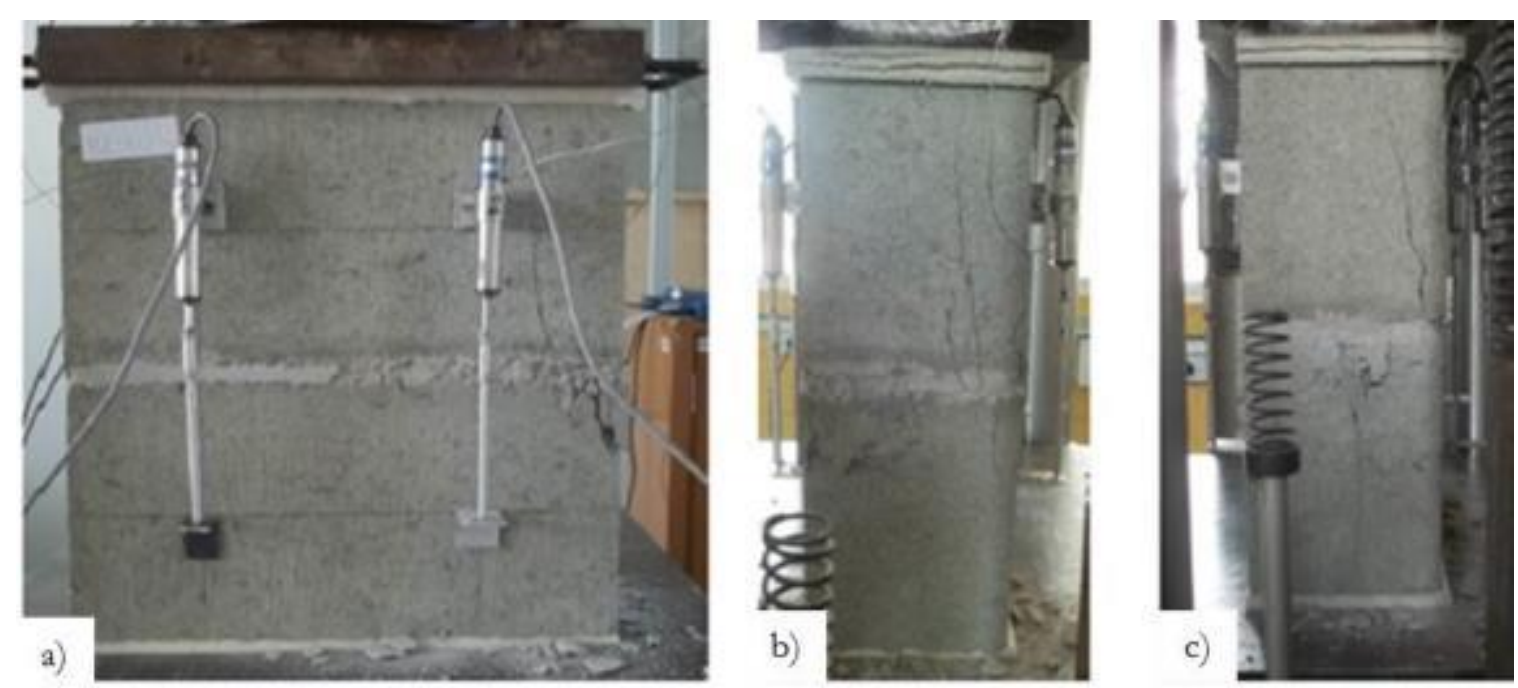

Figura 12: Modo de ruptura do prisma de dois blocos com argamassamento total. Fonte: IZQUIERDO [18]

A Figura 12a mostra uma fissura à direita da face frontal do prisma, mesmo local onde ocorrem as tensões máximas observadas na Figura 11, iniciando-se na argamassa (em vermelho) e se estendendo aos blocos (em amarelo). As Figuras 12b e 12c mostram fissuras nos septos transversais do prisma. Nesses locais também podem ser observadas tensões máximas, conforme a Figura 11. Em IZQUIERDO [18] foi utilizada argamassa com resistência à compressão diferente da empregada nas simulações, por isso comparou-se apenas o modo de ruptura do prisma. Assim, considerou-se que o modo de ruptura numérico do prisma de dois blocos e argamassamento total foi similar ao experimental.

\subsection{Simulações termomecânicas}

3.2.1 Prisma com duas faces expostas ao incêndioEsta simulação de incêndio foi considerada com duração total de três horas. Os campos térmicos desenvolvidos nos blocos e na argamassa estão presentes na Figura 13. 

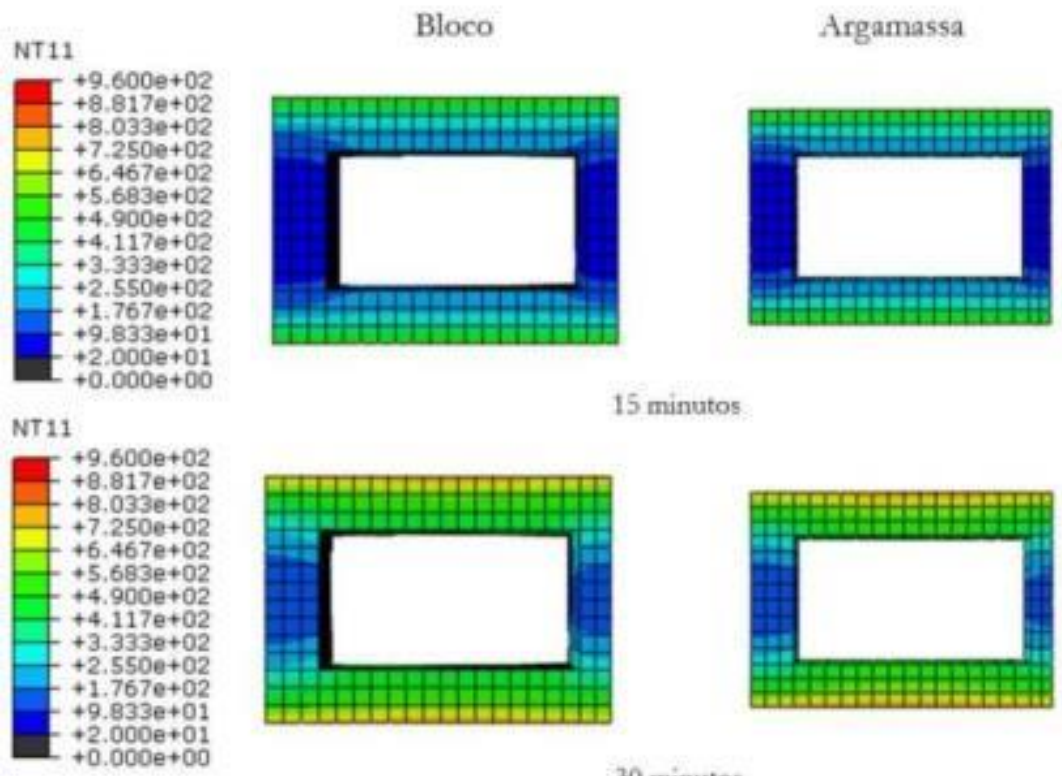

NT 11

30 minutos
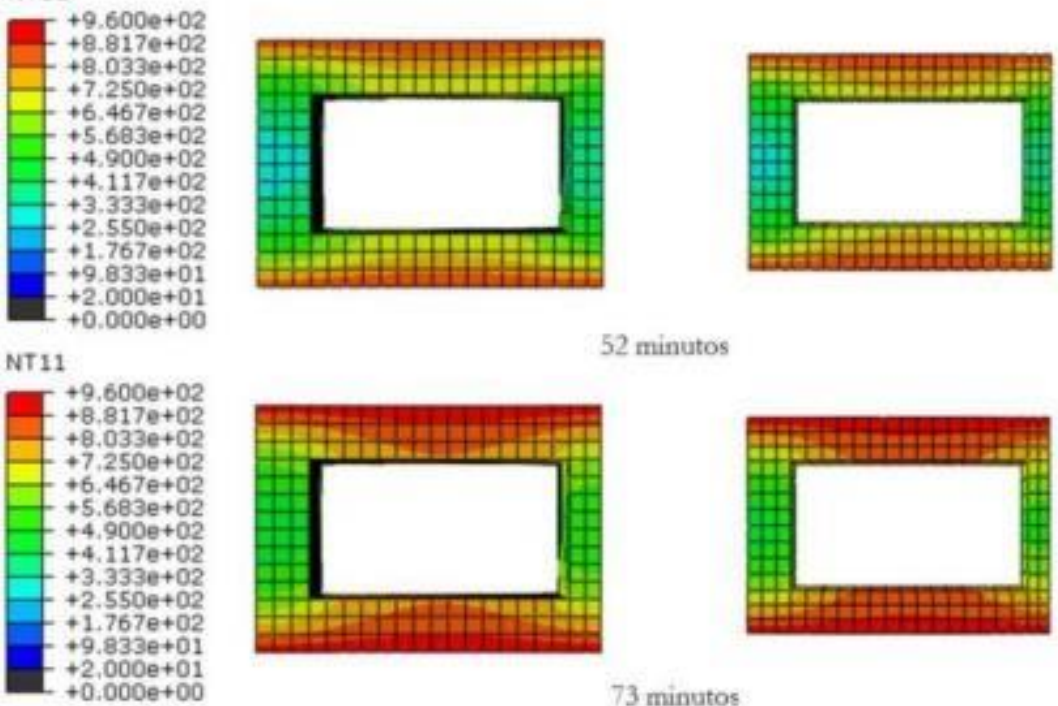

52 minutos

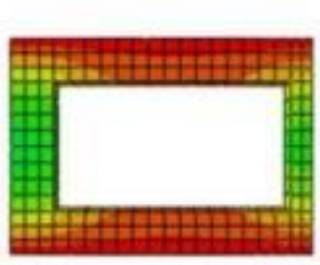

73 minutos

Figura 13: Campos térmicos desenvolvidos no prisma com duas faces expostas ao incêndio $\left({ }^{\circ} \mathrm{C}\right)$.

Na Figura 13 foram apresentados os campos térmicos referentes aos tempos de 52 e 73 minutos de incêndio, pois, apesar de a simulação térmica ter sido processada durante 180 minutos, esses foram os instantes limites de convergência obtidos no ABAQUS para a modelagem termomecânica referente aos carregamentos de 35 e $20 \%$ fpk, respectivamente. A Figura 14 apresenta a deformação axial central do prisma carregado sem restrição vertical e submetido a elevadas temperaturas em duas faces. 


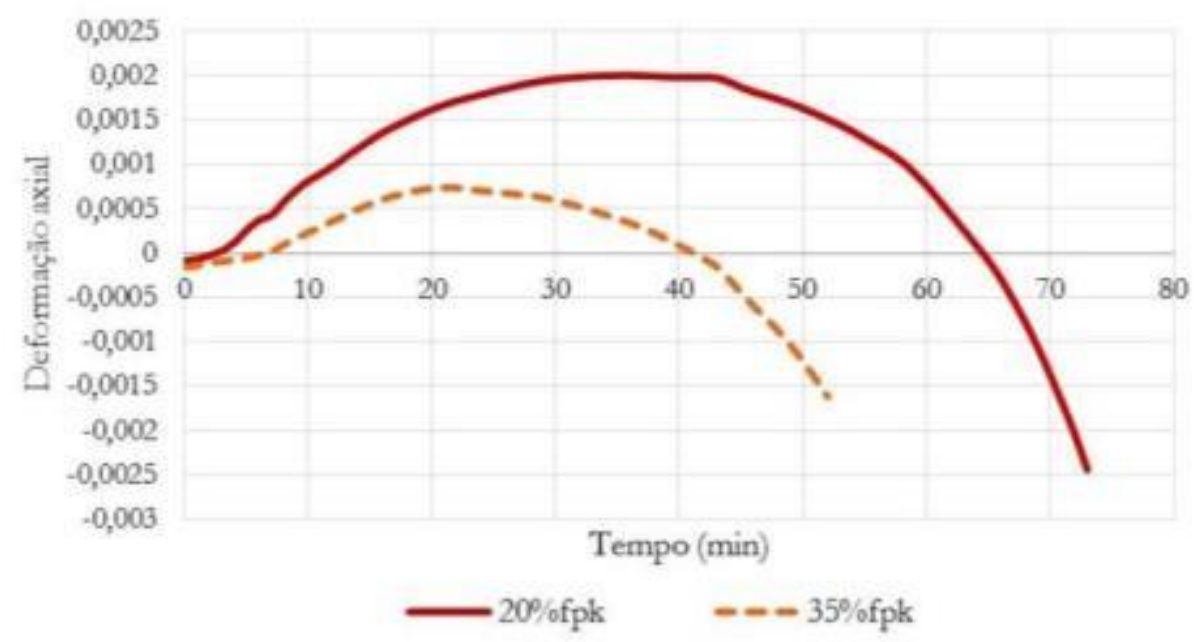

Figura 14: Deformação axial do prisma com duas faces expostas ao incêndio.

Observa-se que, com a elevação de temperatura, os materiais dilatam e após determinados intervalos de tempo, o prisma começa a se encurtar devido à deterioração térmica dos materiais. A ISO 834-1:1999 [6] apresenta dois critérios para se considerar a ruptura do elemento estrutural carregado axialmente, os quais estão descritos nas Equações 3 e 4 em que h é a altura inicial do elemento em milímetros.

Limite de contração axial: $\quad C=\frac{h}{100} \quad(\mathrm{~mm})$

Limite da taxa de contração axial: $\frac{d C}{d t}=\frac{3 h}{1000} \quad(\mathrm{~mm} / \mathrm{min})$

O prisma carregado com 20 e 35\%fpk e com duas faces expostas ao fogo não atingiu esses limites. Outras normas, como EUROCODE 6 PART 1-2:2005 [2] e ABNT NBR 5628:2001 [12], não definem claramente algum critério de ruptura, apenas mencionam a capacidade do elemento de resistir aos esforços para os quais foi projetado durante determinado tempo de incêndio. Assim, optou-se por analisar os resultados finais obtidos através do ABAQUS.

Com a distribuição de temperatura nos materiais, fez-se uma estimativa de suas capacidades resistentes com as curvas tensão-deformação das Figuras 5 e 6, as quais foram inseridas no ABAQUS para a modelagem termomecânica. Para o tempo de 73 minutos, uma região de aproximadamente $67 \mathrm{~cm}^{2}$, considerando o bloco inteiro, está submetida a temperaturas em torno de $500^{\circ} \mathrm{C}$ (tons de verde da Figura 13). Nessas condições, o bloco ainda suporta uma força de $73,7 \mathrm{kN}$ desconsiderando-se o restante do material que está em outras faixas de temperatura, enquanto a força equivalente a $20 \% \mathrm{fpk}$ aplicada no prisma é de aproximadamente 53,0 kN. Assim, conclui-se que a ruptura não foi determinada pelo bloco.

Realizando-se os mesmos cálculos para a argamassa, nota-se que, com 52 minutos de incêndio, ela suportaria uma força aproximada de $72,6 \mathrm{kN}$ de compressão. Após 73 minutos de incêndio sua resistência à compressão cairia para $48,0 \mathrm{kN}$. Como existe o efeito do confinamento, nesse último instante o processamento ainda é possível com o carregamento de $53,0 \mathrm{kN}$. Com uma maior deterioração térmica do material, este suportará uma força inferior a $53,0 \mathrm{kN}$, gerando ruptura teórica e o fim do processamento. Assim, considerou-se que a ruptura do prisma ocorreu no tempo final das simulações, para o caso de carregamento fixo durante o incêndio.

A Figura 15 apresenta a distribuição de tensões principais, máximas e mínimas, para os carregamentos de 20 e 35\%fpk nos instantes considerados de ruptura, com fator escala de deformação igual a 50, para melhor visualização dos resultados. 


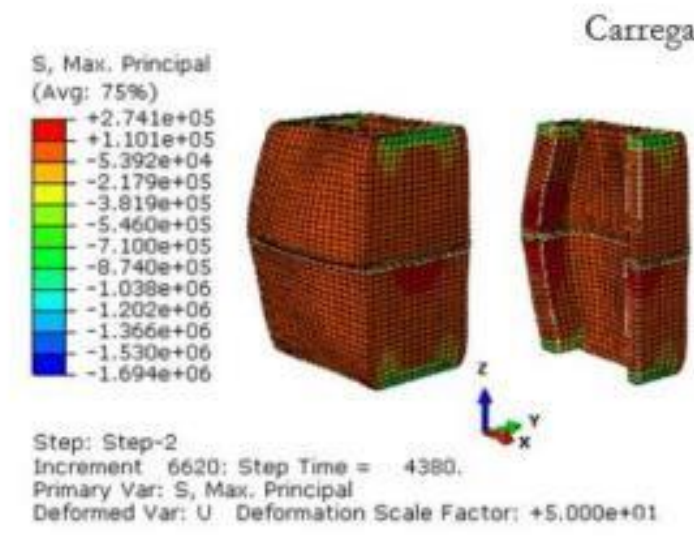

Carregamento $=20 \% \mathrm{fpk}$

S, Min. Principal

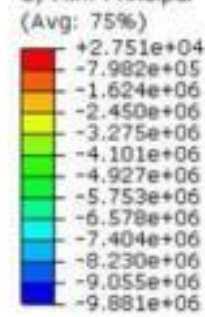

Step: Step-2

Increment $6620:$ Step Time $=4380$.
Primary Var: S, Min. Principal

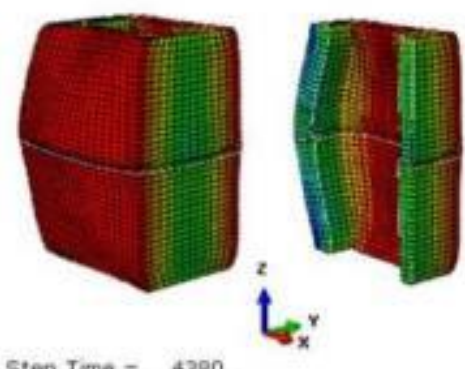

Deformed Var: U Deformation Scale Factor: $+5.000 e+01$

73 minutos

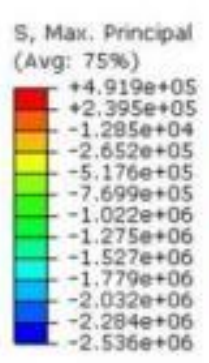

Step: Step=2

Increment 8217 : Step Time = 3120.

Primary Var, S, Max, Principal
Deformed Var: U Deformation Scale Factor: $+5.000 e+01$
Carregamento $=35 \% \mathrm{fpk}$
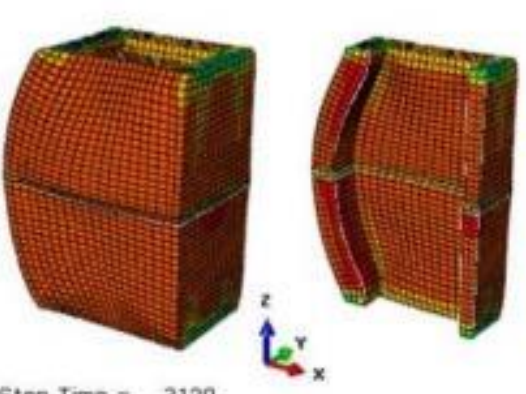

5. Min. Principal (Avg: 75\%)

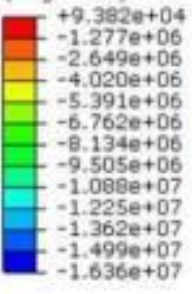

Step: Step-2 Increment 8217: Step Time $=3120$

Primary Var: 5 , Min. Principal

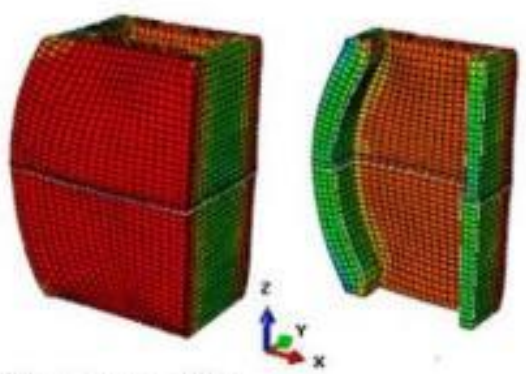

52 minutos

Figura 15: Tensões principais desenvolvidas no prisma com duas faces expostas ao fogo com força constante (Pa).

Observa-se que as faces mais próximas do fogo estão deterioradas, pois não resistem a praticamente nenhuma tensão. A argamassa se encontra mais deformada que os blocos para os dois casos, como esperado.

Neste caso de incêndio em duas faces, foi feita também a verificação com restrição vertical de deslocamento no topo. Para isso, aplicaram-se os carregamentos por meio de um passo inicial e no passo de incêndio restringiu-se o deslocamento na direção $Z$ da placa superior. Assim, a deformação axial do prisma se deve apenas aos carregamentos iniciais e com a restrição vertical têm-se incrementos de força à medida que o prisma tende a aumentar as suas dimensões geométricas por acréscimo de temperatura. Assim, analisaram-se as variações das forças, as quais podem ser observadas na Figura 16, considerando-se o prisma completo, ou seja, carregamento duplicado. 


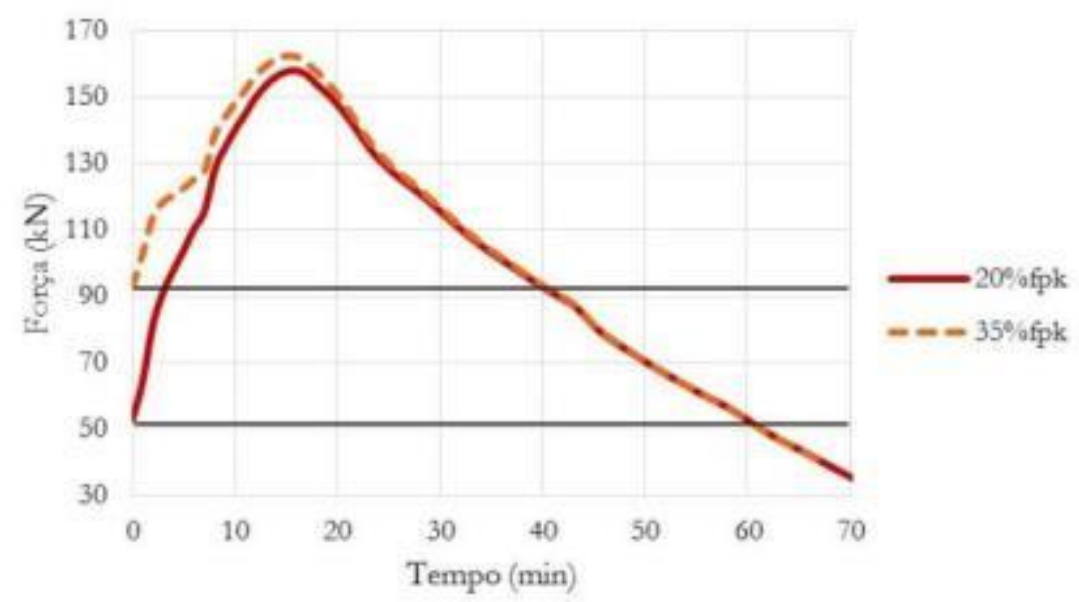

Figura 16: Variações das forças para o prisma com restrição vertical e duas faces expostas ao incêndio.

Com 20\%fpk, o processamento ocorreu durante 180 minutos de incêndio, tempo total da simulação térmica, até a força ficar próxima de zero. Já com 35\%fpk, o processamento foi interrompido após 67 minutos de incêndio com força de, aproximadamente, $41 \mathrm{kN}$. Entretanto, observa-se que para os dois níveis de carregamento, o decréscimo de força após o pico, de aproximadamente $160 \mathrm{kN}$, segue praticamente a mesma taxa.

A falha do critério de resistência mecânica ocorre quando, em determinado tempo de incêndio, o elemento não suporta mais o carregamento para o qual foi projetado. Assim, neste caso considerou-se a ruptura no instante em que a força atinge o valor inicialmente aplicado, conforme feito em NEVES [26]. Então, o prisma com restrição vertical resistiu a 60 e 40 minutos de incêndio com carregamentos de 20 e $35 \%$ fpk, respectivamente. Na Figura 17 estão dispostas as distribuições de tensões principais, máximas e mínimas, nos instantes considerados de ruptura com fator de escala de deformação igual a 50, sendo possível notar a deterioração das faces voltadas ao fogo. 


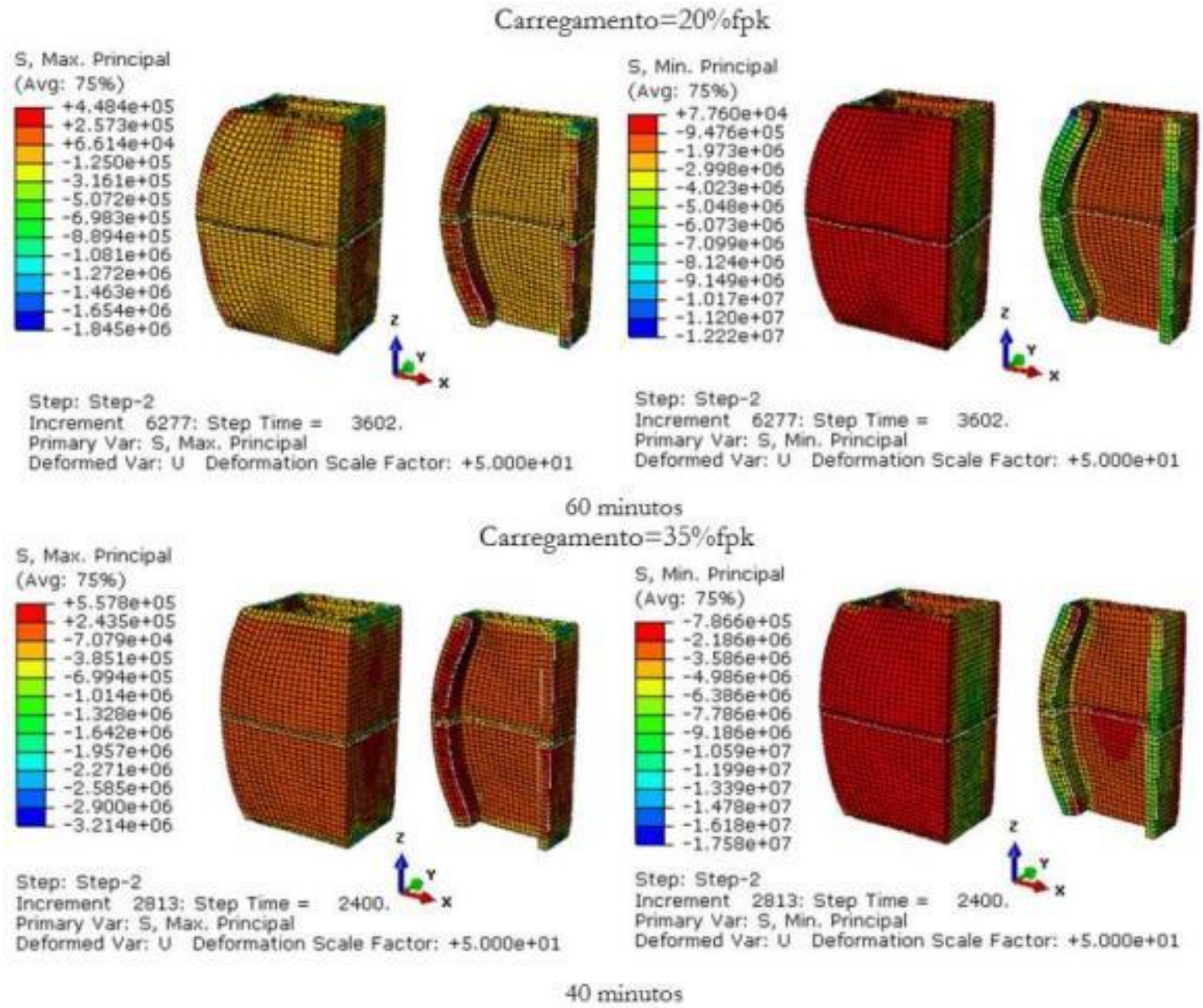

Figura 17: Tensões principais desenvolvidas no prisma com duas faces expostas ao fogo e restrição vertical (Pa).

\subsubsection{Prisma com uma face exposta ao incêndio}

\subsubsection{Carregamento constante com e sem restrição rotacional}

Como o carregamento foi mantido constante durante as simulações de incêndio, analisaram-se os resultados de deformação axial do prisma. Calculou-se a deformação axial em três diferentes pontos do prisma: na face exposta ao incêndio, no centro do prisma e na face exposta à temperatura ambiente. A modelagem com carregamento fixo de $20 \%$ fpk e restrição rotacional foi processada até o tempo final da análise térmica de cinco horas, tempo obtido em RODOVALHO e CORRÊA [9]. Assim, por meio do ABAQUS, a ruptura não foi indicada para esse nível de carregamento. Já com 35\%fpk, o processamento foi interrompido, indicando a ruptura para um tempo de 208 minutos de incêndio. Na Figura 18 está ilustrada a deformação axial do prisma com carregamento fixo e restrição rotacional para os três pontos e dois níveis de carregamento. 


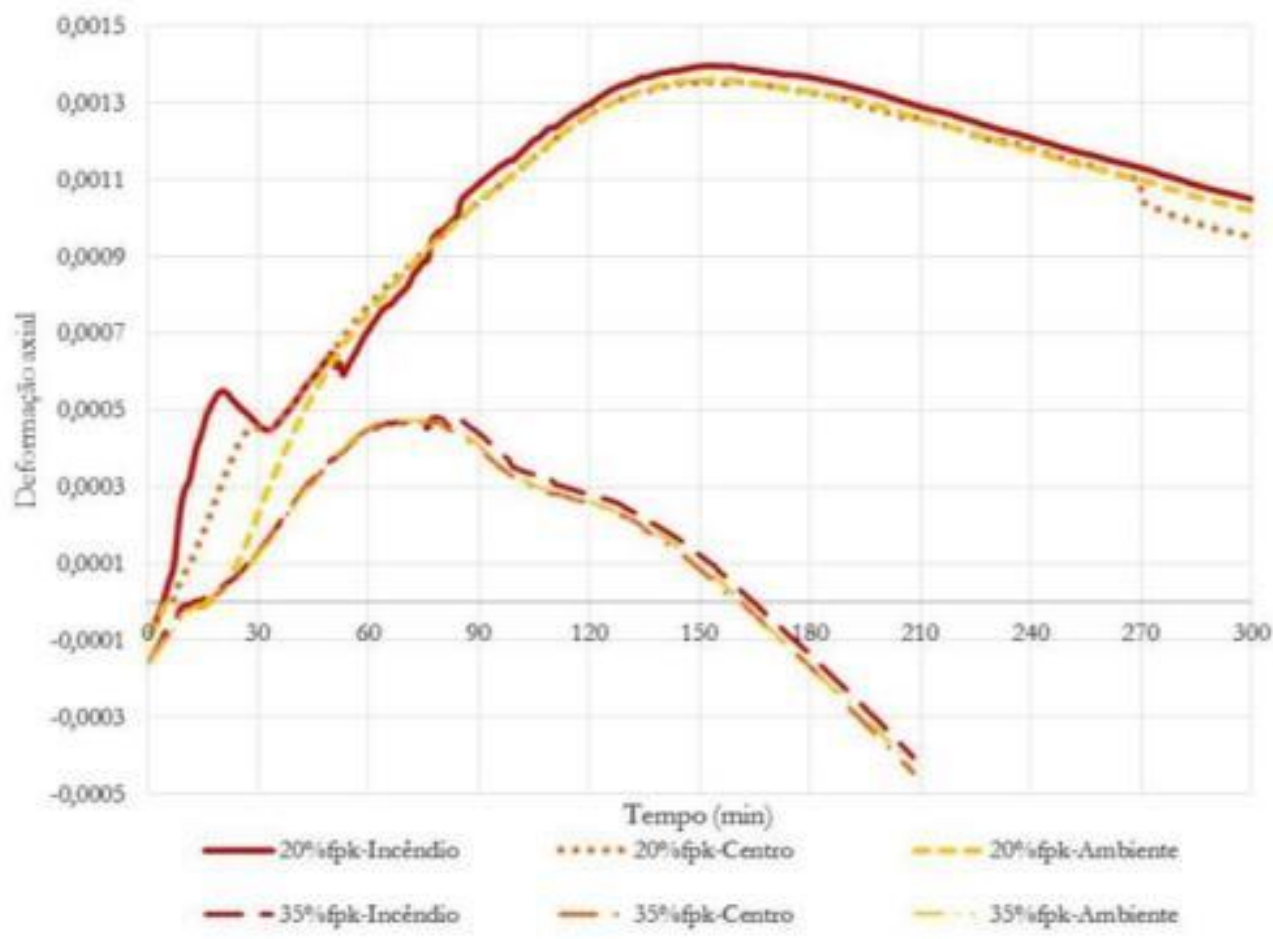

Figura 18: Deformação axial do prisma com uma face exposta ao fogo, carregamento fixo e restrição rotacional.

Observa-se que, antes de 30 minutos, a face exposta ao incêndio se expande mais que o centro e a face exposta ao ambiente, como esperado. Em seguida, devido à restrição rotacional, para o mesmo carregamento, os valores de deformação axial ficam próximos.

As tensões principais, máximas e mínimas, desenvolvidas no prisma para o tempo de 208 minutos e o carregamento de 35\%fpk estão presentes na Figura 19 com fator de escala de deformação de 20. 


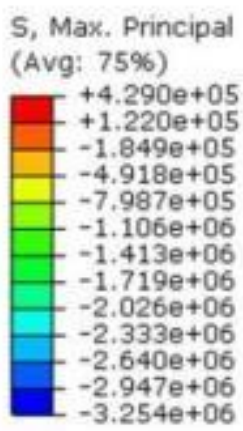

Step: Step-2

Increment $8687:$ Step Time $=1.2483 E+04$
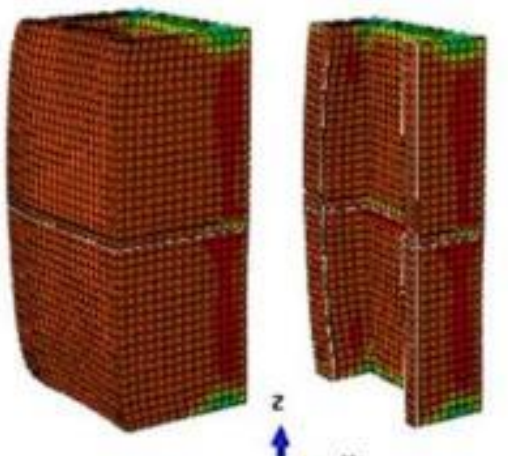

Primary Var: S, Max. Principal

Deformed Var: $U$ Deformation Scale Factor: $+2.000 e+01$

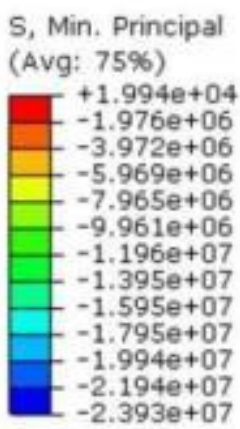

Step: Step-2

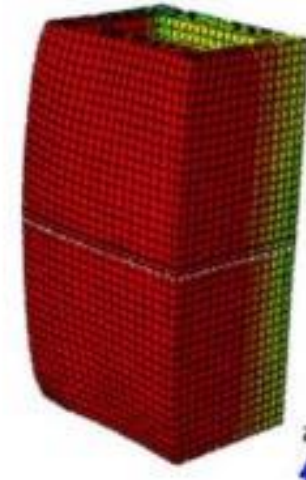

Increment $8687:$ Step Time $=1.2483 \mathrm{E}+04$
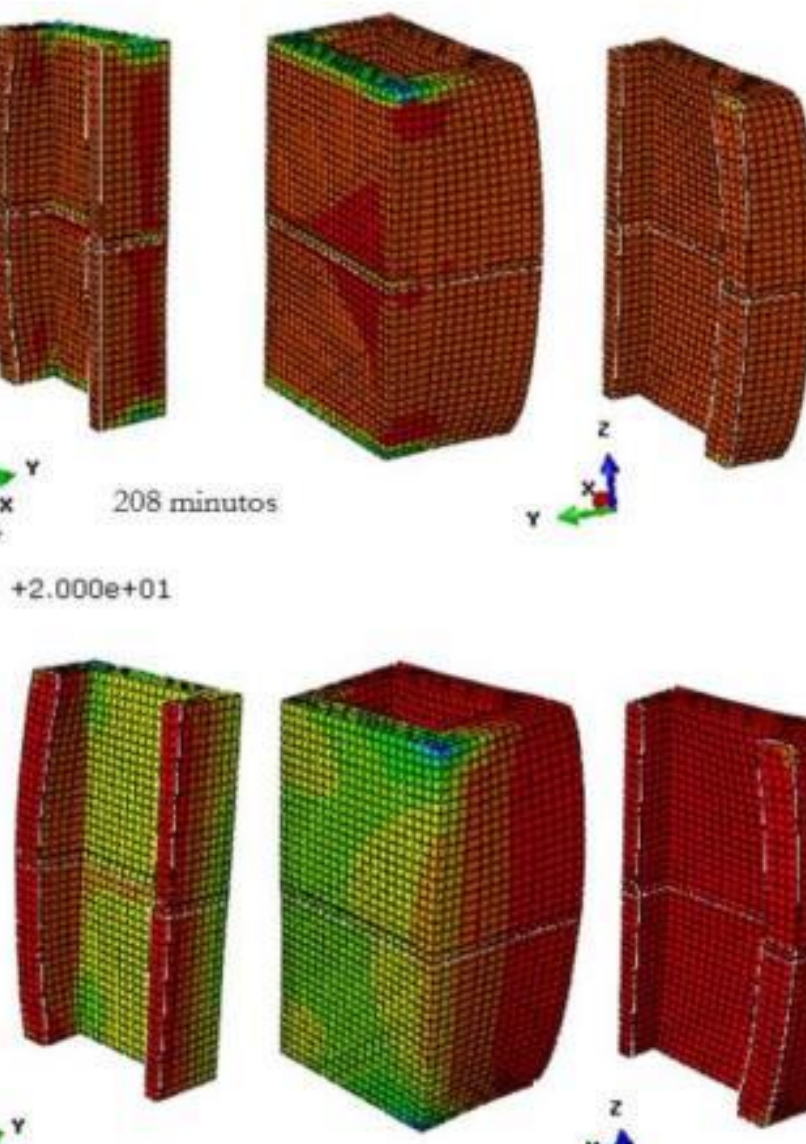

Primary Var: S, Min. Principal

Deformed Var: $U$ Deformation Scale Factor: $+2.000 e+01$

Figura 19: Tensões principais desenvolvidas no prisma com uma face exposta ao fogo para o carregamento de $35 \%$ fpk e restrição rotacional $(\mathrm{Pa})$.

Observa-se o encurvamento do prisma no sentido do fogo. Além disso, nota-se que o material mais próximo do fogo apresenta tensões praticamente nulas indicando que ocorreu a sua deterioração térmica.

Para o caso de carregamento constante e sem restrição rotacional da placa de compressão, também foi analisada a deformação axial do prisma na face exposta ao incêndio, no centro do prisma e na face exposta ao ambiente. Na Figura 20 é apresentada a deformação axial para esses pontos para os dois níveis de carregamento. 


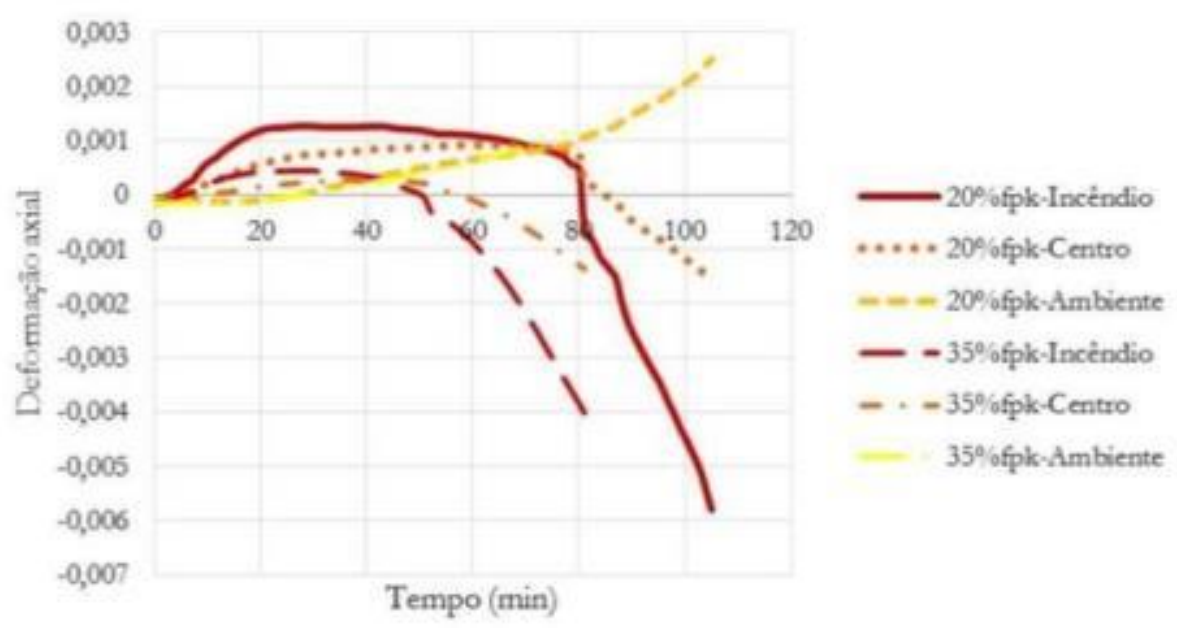

Figura 20: Deformação axial do prisma com uma face exposta ao fogo, carregamento fixo e sem restrição rotacional.

Observa-se que inicialmente ocorreu a expansão da face exposta ao incêndio, enquanto aquela exposta à temperatura ambiente possuía deformação constante. Após determinado intervalo de exposição ao incêndio, para cada carregamento, ocorre uma inversão de tendências. A face exposta ao ambiente passou a se dilatar enquanto ocorreu a contração daquela exposta ao incêndio. O processamento foi interrompido com 105 e 81 minutos para os carregamentos de 20 e $35 \%$ fpk, respectivamente.

A Figura 21 apresenta as tensões principais, máximas e mínimas, para o carregamento de 35\%fpk e sem restrição rotacional no instante de 81 minutos, tempo final de processamento ou instante considerado de ruptura, com fator escala de deformação de 20.

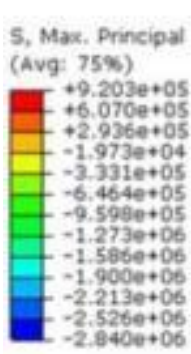

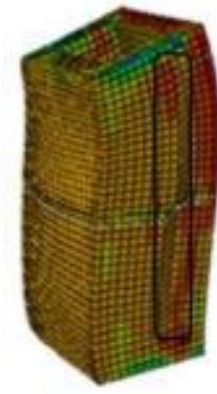

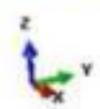

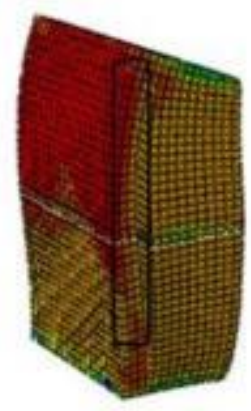

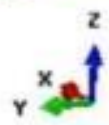

81 minutos
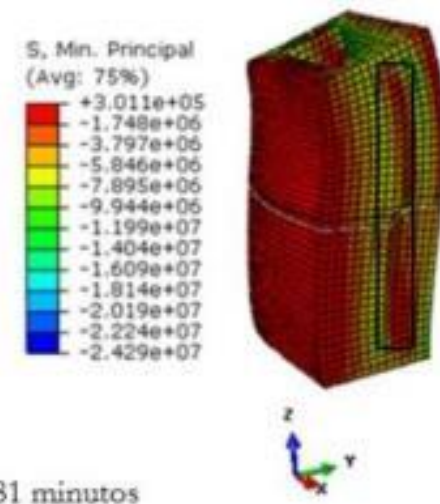

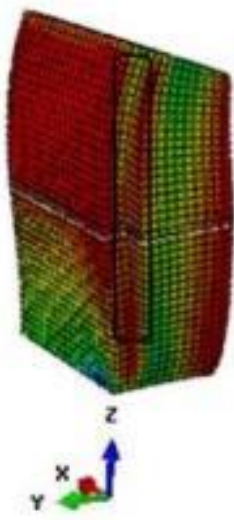

Step: Step-2

Step: Step-2

Increment 5753: Step Time = 4860.

Primary Var: S, Max, Principal

Deformed Vari $U$ Deformation Scale Factor: $+2.000 e+01$

tncrement \$75: Step Time
Primary Var: $\$$, Min. Principal

Deformed var: $U$ Deformation Scale Factor: $+2.0000+01$

Figura 21: Tensões principais desenvolvidas no prisma com uma face exposta ao fogo para o carregamento de $35 \%$ fpk e sem restrição rotacional $(\mathrm{Pa})$.

É possível notar na Figura 21 a rotação do topo do prisma, a qual provoca a rotação da placa de compressão. Além disso, percebe-se que a região do prisma exposta ao fogo está deteriorada. Enquanto a região interna do prisma está suportando tensões de compressão, a região externa, com face exposta ao ambiente, está sujeita a tensões de tração. A ruptura do prisma ocorre entre as regiões tracionada e comprimida, nas áreas destacadas da Figura 21.

\subsubsection{Restrição de deslocamento vertical com e sem restrição rotacional}

Como no caso de carregamento constante com restrição rotacional atingiu-se a ruptura apenas do prisma car- 
regado com 35\%fpk, para possibilitar comparações, foram feitas as simulações apenas deste nível de carregamento.

Conforme feito no caso de incêndio em duas faces, com a imposição de restrição vertical após a aplicação do carregamento, analisaram-se os incrementos de força. Na Figura 22 estão presentes as variações de força para esses dois casos.

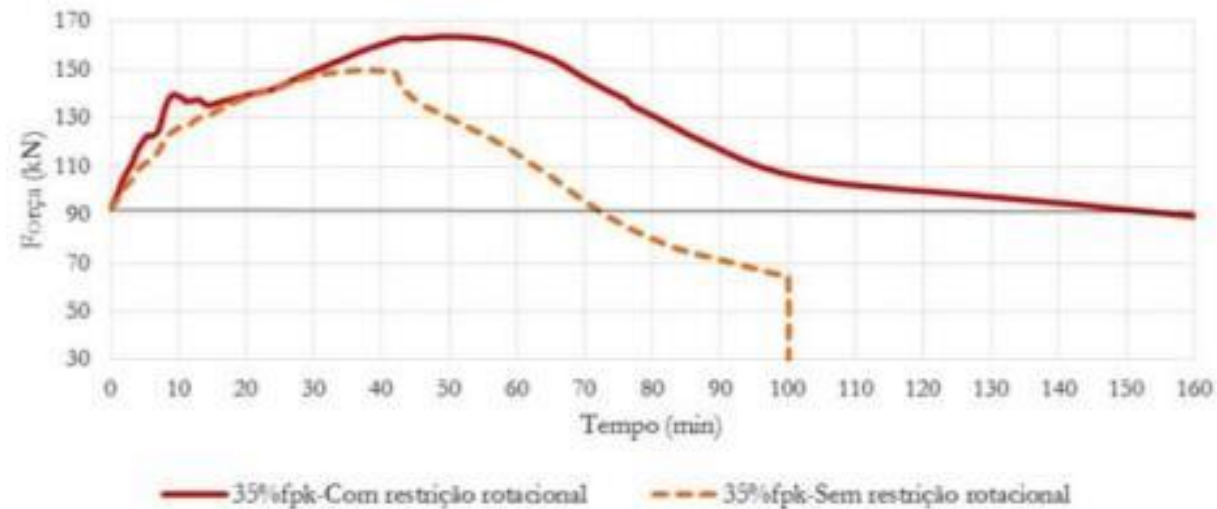

Figura 22: Variações de força para o prisma com restrição vertical e uma face exposta ao fogo.

A força inicialmente aplicada no prisma é atingida em 148 e 72 minutos para os casos com e sem restrição rotacional, respectivamente. Com a restrição rotacional o processamento foi completo, durante 300 minutos de incêndio. Já para o caso sem restrição rotacional ocorreu uma queda brusca da força aos $100 \mathrm{mi}-$ nutos, indicando que ocorreu o tombamento ou escorregamento do prisma, seguida da interrupção do processamento.

As tensões máximas e mínimas principais desenvolvidas no prisma nos instantes em que se atinge a força aplicada inicialmente estão ilustradas na Figura 23 com fator de escala de deformação de 20. 

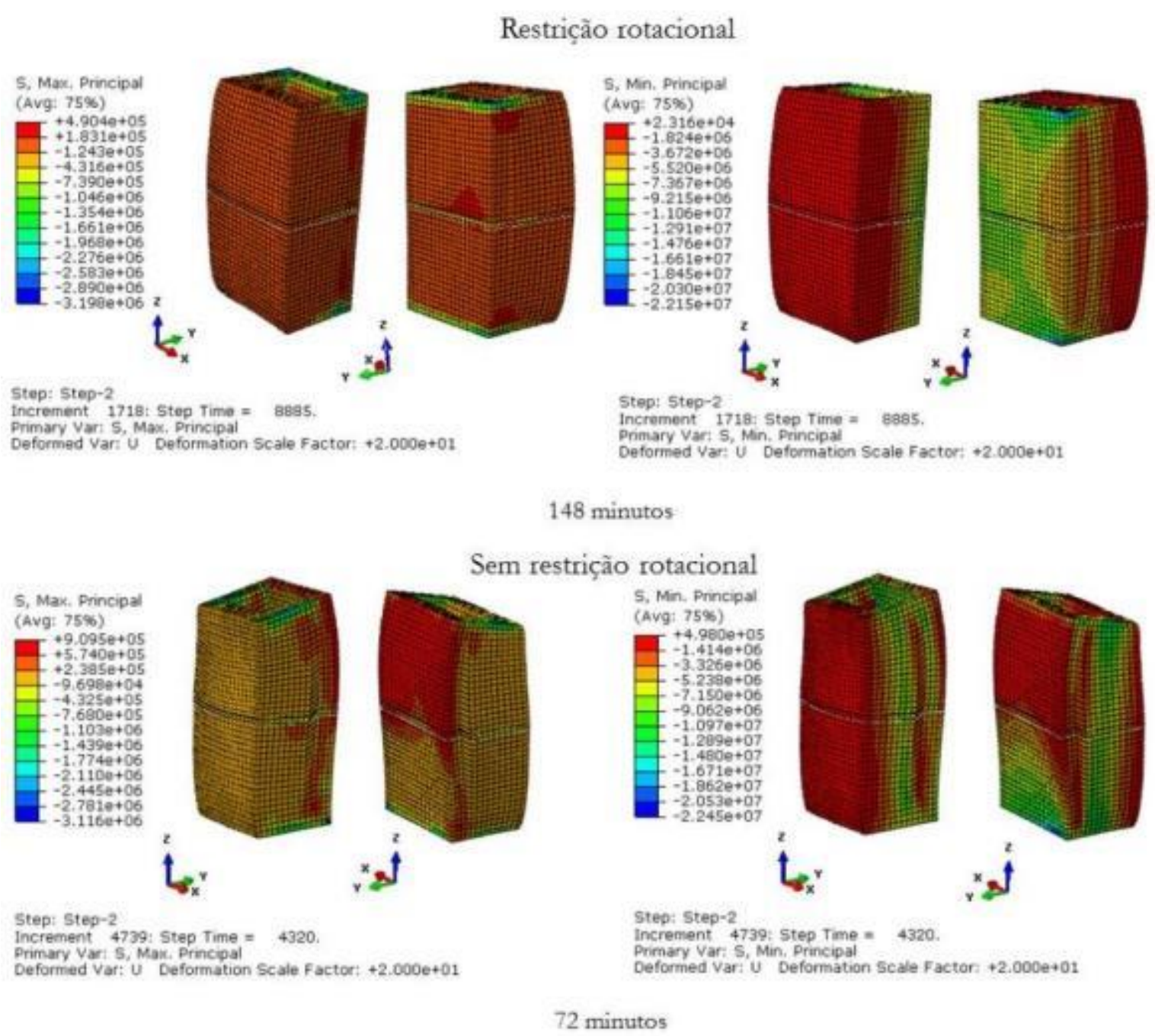

Figura 23: Tensões principais desenvolvidas no prisma com uma face exposta ao fogo, com e sem restrição rotacional e restrição de deslocamento vertical $(\mathrm{Pa})$.

Para o caso sem restrição rotacional é possível notar uma inclinação da parte superior do prisma. A falta de restrição rotacional gera uma distribuição de tensões diferentes daquela restrita.

\section{DISCUSSÃO DOS RESULTADOS}

Nas simulações numéricas de compressão em temperatura ambiente foi possível notar que o prisma de dois blocos apresentou maior resistência quando comparado ao prisma de três blocos, o que é justificado pela adição de uma junta de argamassa que tende a reduzir a resistência dos prismas. Além disso, o efeito do confinamento é mais significativo nos prismas de dois blocos, pois, no caso de três blocos a altura do prisma é maior, ficando o bloco central mais distante das extremidades e, praticamente, sem influência do confinamento.

O tipo de argamassamento também influencia na resistência. Para o argamassamento total existe uma maior área de argamassa, sendo então uma maior área de contato entre os blocos, diminuindo a concentração de tensões nesses componentes. Além disso, no prisma com argamassamento parcial tem-se uma maior indução de tensões de tração nos septos transversais dos blocos.

Nas simulações termomecânicas foram analisados casos sem restrição de deslocamento vertical (S.R.D.V.) ou carregamento constante, com restrição de deslocamento vertical (C.R.D.V.) após a aplicação do carregamento, com e sem restrição rotacional, (C.R.R.) e (S.R.R.), respectivamente. Na Tabela 2 encontram-se os tempos de ruptura ou finais de processamento para cada caso analisado no presente trabalho. 
Tabela 2: Resumo das simulações termomecânicas.

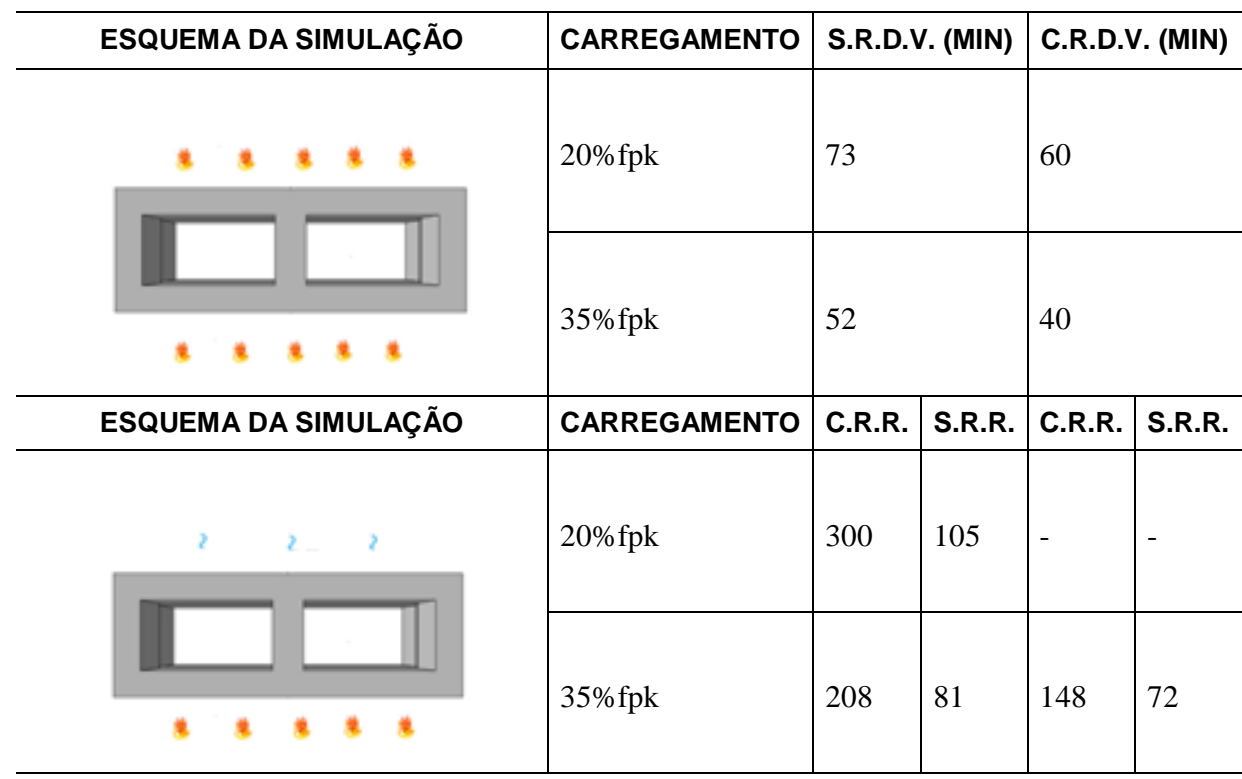

Observa-se que o impedimento de deslocamento vertical e/ou aplicação de um maior valor de carregamento faz com que o elemento resista mecanicamente a um tempo inferior de incêndio, como esperado. Nota-se também através da Tabela 2 que o incêndio nas duas faces foi mais prejudicial ao prisma.

Para os casos com restrição rotacional um momento adicional é gerado que deveria resultar em uma maior deterioração dos materiais no lado exposto ao fogo, e consequente ruptura em tempo inferior ao caso sem restrição rotacional, ao se considerar a compressão. Entretanto aconteceu o contrário. Sem a restrição rotacional surgem tensões de tração na face não exposta ao incêndio, tendo então um modo de ruptura diferente e em tempo inferior aos casos com restrição rotacional.

Considerando-se o caso de carregamento constante conforme especifica a ABNT NBR 5628:2001 [12] e restrição rotacional conforme indicado em NADJAI et al. [25] e RUSSO e SCIARRETTA [23], a aplicação do que seria o "carregamento em serviço do prisma" com o valor de $35 \%$ fpk causou a ruptura do prisma em 208 minutos ou 3h28min para uma face exposta ao incêndio. Conforme CHICHIERCHIO [7] uma parede com função portante sem revestimento manteve-se estável ao fogo durante 4 horas.

De acordo com a ABNT NBR 5628:2001 [12] a resistência mecânica corresponde a 80\% do tempo em que o elemento esteve carregado e em situação de incêndio, até a sua ruína. Então o prisma cuja ruptura se deu em 208 minutos possui resistência mecânica em situação de incêndio de 166 minutos, resultado inferior ao apresentado em CHICHIERCHIO [7]. Ainda assim, conforme RODOVALHO e CORRÊA [9] o critério de isolamento térmico foi o primeiro a falhar com 86 minutos para o prisma sem revestimento.

Para o caso do prisma com revestimento nas duas faces, a perda de isolamento térmico se deu aos 137 minutos, segundo RODOVALHO e CORREAA [9]. Se este possuir resistência mecânica de 166 minutos, como o não revestido, e mantiver-se estanque até a sua ruptura, o prisma com revestimento nas duas faces possuirá grau corta-fogo CF120. Observa-se que, provavelmente, o mesmo possuirá resistência mecânica superior a 166 minutos devido à menor deterioração térmica dos materiais em função da proteção provida pelo revestimento.

\section{CONCLUSÕES}

Inicialmente, em temperatura ambiente foi simulado comportamento do prisma constituído por três blocos de concreto e argamassamento parcial sujeito à compressão. As propriedades necessárias ao modelo de plasticidade do software que não foram obtidas por OLIVEIRA [10] foram calibradas. Obteve-se um bom ajuste entre as curvas experimental e numérica de tensão-deformação até a tensão máxima de compressão. Também foram comparados os modos de ruptura experimental e numérico notando-se similaridade entre eles.

Uma vez que as propriedades do bloco e da argamassa ficaram bem ajustadas para a modelagem do prisma de três blocos com argamassamento parcial, admitiu-se que a compressão em temperatura ambiente do prisma formado por dois blocos e argamassamento total ficaria bem representada. Além disso, comparou- 
se o modo de ruptura numérico e experimental disponível em IZQUIERDO [18] observando-se conformidade entre eles.

Para a modelagem termomecânica, adotou-se a perda de resistência mecânica dos materiais devida à elevação de temperatura, conforme dados disponíveis no EUROCODE 2 PART 1-2:2004 [19]. Nas simulações numéricas aqui apresentadas, o critério de estanqueidade não foi analisado. Entretanto, foram vistos alguns trabalhos nos quais se consideraram a perda de estanqueidade no mesmo instante da perda de resistência mecânica.

Notou-se que a restrição de deslocamento vertical e/ou a aplicação de um maior nível de carregamento antecipa a ruptura do prisma. Além disso, constatou-se que a falta de restrição rotacional gera um modo de ruptura diferente do caso com restrição rotacional e em tempo inferior de incêndio.

A situação de incêndio nas duas faces do prisma causou a sua ruptura teórica em tempo inferior ao caso de incêndio em uma única face, em consequência de sua maior deterioração térmica. Entretanto, para uma parede, o mesmo poderá não acontecer. Por ser um elemento mais esbelto, o efeito do encurvamento produzido pela ação térmica na parede pode ser ainda mais prejudicial que a maior deterioração térmica causada pelo incêndio nas duas faces.

Considerando que os prismas se mantenham estanques até as suas ruínas, aquele sem revestimento foi avaliado por meio das simulações com grau corta-fogo CF60. Contanto que não ocorra o desprendimento da argamassa durante o incêndio, como não ocorreu em OLIVEIRA e BERTO [27], a aplicação de revestimento nas duas faces elevou teoricamente a resistência do prisma para grau corta-fogo CF120, sendo este o maior tempo requerido de resistência ao fogo (TRRF) exigido pela ABNT NBR 14432:2001 [28]. Entretanto, o maior TRRF segundo a INSTRUÇÃO TÉCNICA No 08:2011 [29] é de 180 minutos, dependendo do tipo de ocupação das edificações com altura superior a $120 \mathrm{~m}$.

O emprego da perda de resistência à compressão com propriedades indicadas pelo EUROCODE 2 PART 1-2:2004 [19] levou a um resultado de tempo de resistência mecânica inferior ao apresentado por CHICHIERCHIO [7], sendo favorável à segurança. Entretanto, os resultados das simulações termomecânicas não foram validados com experimentos. Como os prismas são elementos curtos, o efeito do encurvamento térmico não pôde ser detectado como prejudicial às suas resistências.

\section{AGRADECIMENTOS}

Ao Conselho Nacional de Desenvolvimento Científico e Tecnológico pela bolsa concedida.

\section{BIBLIOGRAFIA}

[1] CTIF, Centre of Fire Statistics., World fire statistics. In: Report of International Association of Fire and Rescue Services, n. 23, https://www.ctif.org/sites/default/files/news_files/2019-02/CTIF_Report23_ENGHUN-GER\%20\%281\%29.pdf, acessado em 2018.

[2] EUROPEAN COMMITTEE FOR STANDARDIZATION. Eurocode 6: EN 1996-1.2: design of masonry structures: Part 1-2: general rules: structural fire design. Brussels, 2005.

[3] LEITE, H.A.L., MORENO JÚNIOR, A.L., TORRES, D. L., "Dimensionamento da alvenaria estrutural em situação de incêndio: Contribuição à futura normatização nacional", Ambiente Construído, v. 16, n. 2, pp. 89-107, 2016.

[4] ROSEMANN, F., "Resistência ao fogo de paredes de alvenaria estrutural de blocos cerâmicos pelo critério de isolamento térmico", Dissertação de MSc., 160 p., Universidade Federal de Santa Catarina, Florianópolis, SC, Brasil, 2011.

[5] RIGÃO, A. O., "Comportamento de Pequenas Paredes de Alvenaria Estrutural Frente a Altas Temperaturas", Dissertação de MSc., 142 p., Universidade Federal de Santa Maria, São Maria, RS, Brasil, 2012.

[6] INTERNATIONAL ORGANIZATION FOR STANDARDIZATION. ISO 834: Fire resistance tests elements of building construction: Part 1. General requirements. Gèneve, 1999.

[7] CHICHIERCHIO L. C., Conforto ambiental: desempenho térmico e acústico e proteção contra o fogo. In: Associação Brasileira da Construção Industrializada - ABCI, Manual Técnico de Alvenaria, pp. 119-141, São Paulo, 1990.

[8] BLOCO BRASIL - ASSOCIAÇÃO BRASILEIRA DA INDÚSTRIA DE BLOCOS DE CONCRETO. Manual de Desempenho - Alvenaria com Blocos de Concreto. $2^{\circ}$ Ed, Revisada e Atualizada, 38 p, ISBN 97885-87024-82-4, 2016. 
[9] RODOVALHO, F.S., CORRÊA, M.R.S., "Thermal simulation of prisms with concrete blocks in a fire situation", RIEM - IBRACON Structures and Materials Journal, [S.1.], v. 12, n. 3, ISSN 1983-4195, June of 2019.

[10] OLIVEIRA, L. M. F., "Estudo teórico e experimental do comportamento das interfaces verticais de paredes interconectadas de alvenaria estrutural", Tese de D.Sc (Doutorado em Engenharia de Estruturas), 272 p., Escola de Engenharia de São Carlos, Universidade de São Paulo, São Carlos, SP, Brasil, 2014.

[11] ASSOCIAÇÃO BRASILEIRA DE NORMAS TÉCNICAS. NBR 16522: Alvenaria de blocos de concreto - Métodos de ensaio. Rio de Janeiro, 2016.

[12] ASSOCIAÇÃO BRASILEIRA DE NORMAS TÉCNICAS. NBR 5628: Componentes construtivos estruturais - Determinação da resistência ao fogo. Rio de Janeiro, 2001.

[13] ASSOCIAÇÃO BRASILEIRA DE NORMAS TÉCNICAS. NBR 6136: Blocos vazados de concreto simples para alvenaria - Requisitos. Rio de Janeiro, 2016.

[14] CARREIRA, D. J., CHU, K. H., "Stress-strain relationship for plain concrete in compression", ACI Journal Technical Paper, n. 82-72, 8p, 1985.

[15] BIRTEL, V.; MARK, P., Parameterised finite element modelling of RC beam shear failure. ABAQUS Users' Conference, pp. 95-108, 2006.

[16] FÉDÉRATION INTERNATIONALE DU BÉTON - FIB. Code-type models for structural behavior of concrete. State-of-art report, 2013.

[17] BUTTLER, A. M., FREITAS, PRADO, A. A., CORRÊA, M. R. S., RAMALHO, M. A., "Influência do contato da argamassa com o bloco de concreto nas suas propriedades físicas e mecânicas”, In: XXXII Jornadas Sul-americanas de Engenharia Estrutural, 2006.

[18] IZQUIERDO, O. S., "Estudo da interface bloco/graute em elementos de alvenaria estrutural”, Tese de D.Sc, 322 p., Escola de Engenharia de São Carlos, Universidade de São Paulo, São Carlos, SP, Brasil, 2015.

[19] EUROPEAN COMMITTEE FOR STANDARDIZATION. Eurocode 2: EN 1992-1.2: Design of concrete structures: Part 1-2: General rules - Structural fire design. Brussels, 2004.

[20] ASSOCIAÇÃO BRASILEIRA DE NORMAS TÉCNICAS. NBR 15200: Projeto de estruturas de concreto em situação de incêndio. Rio de Janeiro, 2012.

[21] ASSOCIAÇÃO BRASILEIRA DE NORMAS TÉCNICAS. NBR 15961: Alvenaria estrutural - Blocos de concreto parte 1: Projeto. Rio de Janeiro, 2011.

[22] SCHNEIDER, U., "Concrete at high temperatures - A general review”, Fire Safety Journal, v. 13, pp. 55-68, 1988.

[23] RUSSO, S., SCIARRETTA, F., "Masonry exposed to high temperatures: Mechanical behavior and properties - An overview", Fire Safety Journal, v. 55, pp. 69-86, 2013.

[24] NGUYEN, T. D., MEFTAH, F., "Behavior of clay hollow-brick masonry walls during fire. Part 1: Experimental analysis", Fire Safety Journal, v. 52, pp. 55-64, 2012.

[25] NADJAI, A., O'GARRA, M., ALI, F. A, LAVERTY, D., “A numerical model for the behaviour of masonry under elevated temperatures”, Fire and Materials, v. 27, pp. 163-182, 2003.

[26] NEVES, C. I., "The critical temperature of steel columns with restrained thermal elongation", Fire Safety Journal, v. 24, pp. 211-227, 1995.

[27] OLIVEIRA, C. R. M., BERTO, A. F., Determinação da resistência ao fogo em parede sem função estrutural., In: Relatório de ensaio, IPT, n. 1072 608-203, 12 p, São Paulo, 2015.

[28] ASSOCIAÇÃO BRASILEIRA DE NORMAS TÉCNICAS. NBR 14432: Exigências de resistência ao fogo de elementos construtivos de edificações - Procedimento, Rio de Janeiro, 2001.

[29] CORPO DE BOMBEIROS DO ESTADO DE SÃO PAULO. Instrução Técnica nº8/2011. Resistência ao fogo dos elementos de construção.

\section{ORCID}

Francielle da Silva Rodovalho Márcio Roberto Silva Corrê Jorge Munaiar Neto https://orcid.org/0000-0003-1079-7060

https://orcid.org/0000-0002-6800-7060

https://orcid.org/0000-0002-7241-3950 